\title{
Dystroglycan Mediates Clustering of Essential GABAergic Components in Cerebellar Purkinje Cells
}

\author{
Federica Briatore ${ }^{1+}$, Giulia Pregno ${ }^{1+}$, Silvia Di Angelantonio ${ }^{2,3}$, Elena Frola ${ }^{1}$, \\ Maria Egle De Stefano ${ }^{4}$, Cyrille Vaillend ${ }^{5}$, Marco Sassoè-Pognetto ${ }^{*}$ and \\ Annarita Patrizi ${ }^{1,6 *}$
}

\begin{abstract}
'Department of Neuroscience "Rita Levi Montalcini", University of Turin, Turin, Italy, ${ }^{2}$ Department of Physiology and Pharmacology, Sapienza University of Rome, Rome, Italy, ${ }^{3}$ Center for Life Nanoscience, Istituto Italiano di Tecnologia, Rome, Italy, ${ }^{4}$ Department of Biology and Biotechnology "Charles Darwin", Istituto Pasteur Italia-Fondazione Cenci Bolognetti, Sapienza University of Rome, Rome, Italy, ${ }^{5}$ CNRS, Institut des Neurosciences Paris-Saclay, Université Paris-Saclay, Gif-sur-Yvette, France, ${ }^{6}$ Schaller Research Group Leader at the German Cancer Research Center, Heidelberg, Germany
\end{abstract}

\section{OPEN ACCESS}

Edited by:

Masahito Yamagata

Harvard University, United States

Reviewed by:

Taisuke Miyazaki,

Hokkaido University, Japan

Bo Zhang,

Peking University, China

*Correspondence:

Marco Sassoè-Pognetto

marco.sassoe@unito.it

Annarita Patrizi

a.patrizi@dkfz-heidelberg.de

†These authors have contributed equally to this work

Received: 22 June 2020 Accepted: 11 August 2020 Published: 28 August 2020

Citation:

Briatore F, Pregno $G$, Di Angelantonio S, Frola $E$, De Stefano ME, Vaillend $C$, Sassoè-Pognetto $M$ and Patrizi $A$

(2020) Dystroglycan Mediates Clustering of Essential GABAergic Components in Cerebellar Purkinje Cells. Front. Mol. Neurosci. 13:164. doi: 10.3389/fnmol.2020.00164
Muscle dystrophin-glycoprotein complex (DGC) links the intracellular cytoskeleton to the extracellular matrix. In neurons, dystroglycan and dystrophin, two major components of the DGC, localize in a subset of GABAergic synapses, where their function is unclear. Here we used mouse models to analyze the specific role of the DGC in the organization and function of inhibitory synapses. Loss of full-length dystrophin in $m d x$ mice resulted in a selective depletion of the transmembrane $\beta$-dystroglycan isoform from inhibitory post-synaptic sites in cerebellar Purkinje cells. Remarkably, there were no differences in the synaptic distribution of the extracellular $\alpha$-dystroglycan subunit, of $\mathrm{GABA}_{\mathrm{A}}$ receptors and neuroligin 2. In contrast, conditional deletion of the dystroglycan gene from Purkinje cells caused a disruption of the DGC and severely impaired post-synaptic clustering of neuroligin 2, GABA $\mathrm{A}$ receptors and scaffolding proteins. Accordingly, whole-cell patch-clamp analysis revealed a significant reduction in the frequency and amplitude of spontaneous IPSCs recorded from Purkinje cells. In the long-term, deletion of dystroglycan resulted in a significant decrease of GABAergic innervation of Purkinje cells and caused an impairment of motor learning functions. These results show that dystroglycan is an essential synaptic organizer at GABAergic synapses in Purkinje cells.

Keywords: neuroligin 2, GABA receptors, cell adhesion molecules, dystrophin, synapse organizer

\section{INTRODUCTION}

Synapse formation is a key step in the development of neuronal networks. Research over the past few decades has led to the identification of several factors that play a role in the assembly, maturation and remodeling of synaptic connections, and provide a basis for the molecular and functional specificity of synapses (Shen and Scheiffele, 2010; Yogev and Shen, 2014). It is believed that cell type-specific formation of a nascent synapse and its subsequent maturation, involving the assembly of pre- and post-synaptic signaling machinery, are mainly mediated by synaptic celladhesion molecules (Yamagata et al., 2003). Interestingly, a substantial number of different synaptic cell-adhesion systems have been shown to control the formation of glutamatergic synapses, through specific PDZ-binding domains (Siddiqui and Craig, 2011). In contrast, GABAergic post-synaptic 
compartments comprise very few PDZ-domain-containing proteins and instead require gephyrin, a scaffolding protein, to accumulate $\mathrm{GABA}_{\mathrm{A}}$ receptors $\left(\mathrm{GABA}_{\mathrm{A}} \mathrm{Rs}\right.$ ) (Tyagarajan and Fritschy, 2014). GABAergic synapses also contain selective celladhesion proteins, such as neuroligin 2 (NL2) (Varoqueaux et al., 2004), and in some cases the dystrophin-glycoprotein complex (DGC) has been shown to play a role in inhibitory synaptic function (Anderson et al., 2003; Kueh et al., 2008; Pribiag et al., 2014).

The DGC is a large, membrane-spanning protein complex that links the extracellular matrix to the actin-associated cytoskeleton in both skeletal muscle and non-muscle tissues (Barresi and Campbell, 2006). The DGC can be resolved into three classes of proteins: (1) $\alpha$ and $\beta$-dystroglycan (DG), (2) the cytoplasmatic subcomplex composed by dystrophin and dystrobrevin, and (3) the sarcoglycan complex (Blake et al., 2002). Studies on brain have revealed that the DGC is expressed both in glia and in neurons, and is localized post-synaptically in a subset of inhibitory synapses, where its stoichiometric composition and function remain poorly characterized (Blake et al., 1999; Moukhles and Carbonetto, 2001).

The importance of the DGC for brain function is testified by clinical observations revealing that dystrophies, a group of muscular diseases driven by mutation of dystrophin, and dystroglycanopathies, a heterogenous group of muscular dystrophies caused by hypoglycosylation of $\alpha-D G$ with O-linked carbohydrates (Martin, 2005), are frequently accompanied by cognitive impairments and epilepsy with or without structural brain abnormalities (Godfrey et al., 2011; Devisme et al., 2012).

Dystroglycan is present in a subset of GABA synapses in forebrain neurons and cerebellar Purkinje cells (PCs), where it co-localizes with other members of the GABAergic post-synaptic specialization (Levi et al., 2002; Grady et al., 2006; Briatore et al., 2010). It comprises two subunits, the extracellular $\alpha$-DG and the transmembrane $\beta$-DG, derived from post-translational cleavage of a precursor polypeptide (Ibraghimov-Beskrovnaya et al., 1992). The $\alpha$ subunit is heavily glycosylated and binds with high affinity to laminin and other laminin G (LG)-like domaincontaining molecules, such as agrin, perlecan and pikachurin, via O-linked sugar chains associated with its central mucin domain (Barresi and Campbell, 2006; Muntoni et al., 2007; Goddeeris et al., 2013). The $\beta$ subunit has a single transmembrane domain that binds dystrophin at its cytoplasmic tail and extracellularly interacts with $\alpha$-DG (Ervasti and Campbell, 1993). Biochemical studies have revealed that at synapses the $\alpha / \beta-D G$ complex can interact both with presynaptic adhesion proteins, such as NRX and NRX-like family components (Sugita et al., 2001; Siddiqui and Craig, 2011), and with post-synaptic intracellular scaffolds, such as S-SCAM, a member of the membraneassociated guanylate kinase (MAGUK) family of PDZ-domaincontaining proteins. In turn, the PDZ domain of S-SCAM interacts with the C-terminal tail of NL2, linking the NRX-NL adhesion system with the DGC (Sumita et al., 2007). Thus, $\alpha / \beta$ DG binds to essential extracellular and intracellular synaptic components, supporting the idea that it is a suitable candidate as a mediator of synaptic specificity (Sassoe-Pognetto and Patrizi,
2017). However, the role of DG in trans-synaptic signaling is poorly characterized (Sugita et al., 2001; Früh et al., 2016).

In the present study, we explored the role of DG in GABAergic synapse organization in PCs. We show that DG is required for post-synaptic localization of NL2, GABA $\mathrm{N}_{\mathrm{A}}$ and S-SCAM. Deletion of DG causes a severe reduction of GABAergic innervation of PCs, and affects motor learning, indicating that GABAergic synapses are critically dependent on DG in vivo. Furthermore, comparison of conditional DG knockout (KO) mice with $m d x$ mice lacking full-length dystrophin indicates that the extracellularly-located $\alpha-D G$ acts as a major organizer of GABAergic synapses. These results suggest that trans-synaptic interactions mediated by $\alpha-D G$ regulate the organization and maintenance of GABAergic synapses in cerebellar PCs.

\section{MATERIALS AND METHODS}

\section{Mice}

Adult $m d x$ mice (C57BL/10ScSn-Dmd $\left.{ }^{m d x} / \mathrm{J}\right)$ lacking dystrophin and $\mathrm{C} 57 \mathrm{BL} / 10 \mathrm{~J}$ controls were used in the study (Vaillend et al., 2004). Mice carrying a floxed version of the Dag1 gene (Cohn et al., 2002) were purchased from the Jackson laboratory (129-Dag1 $1^{\mathrm{TM} 2 \mathrm{Kcam}} / \mathrm{J}$, \# 006835). The homozygous mice were crossed with mice hemizygous for L7Cre transgene (Barski et al., 2000). Littermates of the following genotypes were used for the experiments: Dag1lx/Dag1lx/L7Cre (PC$\triangle \mathrm{DG})$ and Dag1lx/Dag1lx (c-WT). Briefly, mice were genotyped by PCR analysis of genomic DNA from biopsies using the following primer pairs: DG1 (5'-GGAGAGGATCAATCATGG$\left.3^{\prime}\right)$ plus DG2 (5'-CAACTGCTGCATCTCTAC-3') to test for the Dag1 allele (516 bp band for wt, 615 bp band for mutant); Cre1 (5'-GACCAGGTTCGTTCACTCATGG-3') plus Cre2 (5'-AGGCTAAGTGCCTTCTCTACAC-3') to test for the Cre recombinase transgene (250 bp band for L7Cre).

The experimental procedures were designed in accordance with national (Legislative Decree $116 / 92$ and law $n$. 413/1993) and international (Directive 86/609/EEC and the recommendation 2007/526/EC from the Europen Community) laws and policies, and approved by the Italian Ministry of Health (Department of Public Veterinary Health) and by the ethical committee of Turin University. All efforts were made to minimize the animal suffering and the number of animals used.

\section{Immunofluorescence}

For detection of post-synaptic molecules, we used the protocol described in Patrizi et al. (2008). Briefly, mice were anesthetized and decapitated, the brains were excised and the cerebellum was cut manually in sagittal slabs that were fixed by immersion in ice-cold formaldehyde ( $4 \%$ in $0.1 \mathrm{M}$ phosphate buffer, $\mathrm{PB}$, $\mathrm{pH}$ 7.4) for $30 \mathrm{~min}$. For detection of presynaptic molecules, mice were perfused with $4 \%$ formaldehyde in $\mathrm{PB}$, and their brains were post-fixed overnight. Tissue slabs were cryoprotected in sucrose, sectioned with a cryostat, and the sections were collected on gelatin-coated slides. Following a blocking step in normal goat or donkey serum (3\% in PBS with $0.5 \%$ Triton X-100), the sections were incubated overnight with 
a combination of the following antibodies: anti-GABA $\mathrm{R} \alpha 1$ (rabbit, 1:5000) and anti-GABA $\mathrm{R} \gamma 2$ (guinea pig, 1:2000) kindly provided by Dr. J.-M. Fritschy (University of Zurich, Switzerland); anti-neuroligin 2 (NL 2) (rabbit, 1:2000) kindly provided by Dr. F. Varoqueaux (Max-Planck Institute of Experimental Medicine, Göttingen, Germany); anti-carbonic anhydrase 8 (Car8) (guinea pig, 1:500) kindly provided by Dr. M. Watanabe (University School of Medicine, Sapporo, Japan); anti-gephyrin (mouse, 1:1000, \#147 011) and anti-VGAT (rabbit, 1:3000, \#131 003) purchased from Synaptic Systems (SYSY, Germany); anti-dystrophin (mouse, 1:20, \#DYS2-CE-S) and anti- $\beta$-dystroglycan (mouse, 1:500, \#B-DG-CE) purchased from Leica Biosystem (Buffalo Grove, IL, United States); anti- $\alpha$-dystroglycan (mouse, 1:100, \#05-298, clone VIA4-1, Upstate-Millipore, Germany); anti-S-SCAM/MAGI-2 (rabbit, 1:100, \#M2441, Sigma-Aldrich, Germany); anti-bassoon (mouse, 1:3000, \#VAM-PS003, clone SAP7F407, Enzo Life Science, East Farmingdale, NY, United States); anti-calbindin (mouse, 1:10000, \#300, Swant, Switzerland); anti-GAD65 (mouse, 1:1000, \#GAD6, Developmental Studies Hybridoma Bank, Iowa City, IA, United States). The sections were then rinsed and incubated with the appropriate secondary antibodies, raised either in goat or in donkey, conjugated to one of the following fluorophores: Alexa 488 and Alexa 568 (Molecular Probes, Eugene, OR, United States), or the cyanine-derived Cy3 and Cy5 (Jackson Immunoresearch, West Grove, PA, United States). The sections were rinsed again and coverslipped with Dako fluorescence mounting medium (Dako Italia, Italy).

\section{Confocal Microscopy and Data Analysis}

The sections were analyzed with a laser-scanning confocal microscope (Zeiss LSM5 Pascal, Germany) using the multichannel acquisition mode to avoid fluorescence crosstalk. Quantitative analyses were performed on a minimum of three mice per group. Synaptic structures were analyzed on images acquired with $\mathrm{a} \times 100$ oil-immersion objective ( 1.4 numerical aperture) at a magnification of $8.1 \times 10^{-3} \mu \mathrm{m}^{2} /$ pixel, and the pinhole set at 1 Airy unit. The images were processed with the image-analysis program Imaris (release 4.2; Bitplane, Zurich, Switzerland). After segmentation, synapse density was quantified with NIH Fiji:Image J software ${ }^{1}$. In PC- $\Delta D G$ mice, quantitative analysis of the number of PCs expressing DG was done with $\alpha$-DG immunostaining. The number of perisomatic and axodendritic synapses was determined by counting manually synaptic clusters at the surface of PCs, some of which were labeled for Car8 or calbindin. Gephyrin clusters were quantified only at axo-dendritic synapses due to the absence of gephyrin at mature perisomatic synapses (Viltono et al., 2008). For pinceau analysis, we measured both the area covered by VGAT staining and the mean pixel intensity of the single VGAT-positive pinceau using NIH Fiji:Image J software.

\section{Electron Microscopy}

Mice aged 6 months or more were perfused with $1 \%$ formaldehyde and 1\% glutaraldehyde in PB. The cerebellum

${ }^{1}$ https://imagej.net/Fiji was dissected, post-fixed in the same fixative overnight, and the vermis was cut into sagittal sections with a scalpel. The sections were post-fixed in osmium tetroxide $(1 \%$ in $0.1 \mathrm{M}$ cacodylate buffer), dehydrated in ethanol and embedded in Epon-Araldite. Ultrathin sections were collected on copper mesh grids, stained with uranyl acetate and lead citrate and observed with a JEM1010 and a JEM-1400Flash electron microscope (Jeol, Japan) equipped with a side-mounted sCMOS camera. The number of perisomatic synapses was determined by counting synaptic boutons at the surface of PCs.

\section{Immunogold Labeling}

Adult mice (aged 3 months) were perfused with 2\% formaldehyde and $0.1 \%$ glutaraldehyde in sodium acetate buffer, followed by $1 \mathrm{~h}$ perfusion with $2 \%$ formaldehyde and $0.1 \%$ glutaraldehyde in $0.1 \mathrm{M}$ borate buffer. Brains were post-fixed in the second fixative solution overnight. Tissue blocks from the cerebellar vermis were freeze-substituted and embedded in Lowicryl HM20. Ultrathin sections were processed for the immunogold method using as secondary antibodies goat Fab fragments coupled to $10 \mathrm{~nm}$ colloidal gold particles (Sassoe-Pognetto and Ottersen, 2000).

\section{Electrophysiology \\ Slice Preparation}

Cerebellar slices were routinely prepared from PC- $\triangle \mathrm{DG}$ and wild-type (c-WT) littermate controls, at different postnatal weeks. Mice were decapitated under halothane anesthesia, and whole brains were rapidly removed and incubated in chilled, oxygenated $\left(95 \% \mathrm{O}_{2}, 5 \% \mathrm{CO}_{2}\right)$ glycerol-based cutting solution (in mM): $2.5 \mathrm{KCl}, 2.4 \mathrm{CaCl}_{2}, 1.2 \mathrm{MgCl}_{2}, 1.2 \mathrm{NaHPO}_{4}, 26$ $\mathrm{NaHCO}_{3}, 11$ glucose, 250 glycerol. Sagittal cerebellar slices $(250 \mu \mathrm{m})$ were cut at $4^{\circ} \mathrm{C}$, using a Vibratome (DSK, Dosaka EM, Kyoto, Japan). Before use, slices were maintained for at least $1 \mathrm{~h}$ at room temperature $\left(22-25^{\circ} \mathrm{C}\right)$ in oxygenated (95\% $\mathrm{O}_{2}, 5 \% \mathrm{CO}_{2}$ ) ACSF, containing the following (in $\mathrm{mM}$ ): $125 \mathrm{NaCl}, 2.5 \mathrm{KCl}, 1.25 \mathrm{NaH}_{2} \mathrm{PO}_{4}, 26 \mathrm{NaHCO}_{3}, 2 \mathrm{CaCl}_{2}$, $1 \mathrm{MgCl}_{2}$, and 10 glucose, $\mathrm{pH}$ 7.35. All recordings were performed at room temperature on slices submerged in ACSF in the recording chamber. The ACSF was perfused at a rate of $1 \mathrm{ml} / \mathrm{min}$.

\section{Patch-Clamp Recording}

Neurons were visualized at $\times 640$ with Nomarski optics with an upright Zeiss Axioscope microscope. Patch-clamp recordings were obtained using glass electrodes (3-5 M $\Omega$ ) filled with the following (in $\mathrm{mM}$ ): 140 Cs-methanesulfonate, $2 \mathrm{MgCl}_{2}, 10$ HEPES, 2 MgATP, 0.5 EGTA; pH 7.3, with CsOH. Neurons were clamped at -70 or $0 \mathrm{mV}$. Membrane currents, recorded with a patchclamp amplifier (Axopatch 200A; Molecular Devices), were filtered at $2 \mathrm{kHz}$, digitized $(10 \mathrm{kHz})$, and acquired with Clampex 10 software (Molecular Devices). The stability of the patch was checked by repetitively monitoring the input and series resistance during the experiment, and recordings were discarded when any of these parameters changed by $10 \%$. Data were analyzed offline with Clampfit 10 (Molecular Devices). 


\section{Behavioral Analysis}

\section{Behavioral Tests Were Performed Blind to the Genotype \\ Inverted screen}

PC- $\triangle \mathrm{DG}$ and littermate controls were placed individually on a cage wire screen about $35 \mathrm{~cm}$ above a table. After slowly inverting the screen upside-down to $180^{\circ}$, the ability to maintain a grip was monitored (grip latency) and a maximum score of 120 was given if the animal did not fall. Testing was repeated three times with 10-min inter-trial intervals.

\section{Wire suspension}

The front paws of the mice were positioned on a horizontal steel wire $(0.6 \mathrm{~mm}$ thick) suspended at a height of $30 \mathrm{~cm}$ above a table. Three trials spaced by a 5 -min pause were performed with each trial limited to $60 \mathrm{~s}$ duration. The latency to touch the wire with one hind paw were recorded during each trial; a mean score was then calculated. Other qualitive parameters were recorded and a score was attributed corresponding to the best performance achieved within the minute of testing according to the following scale (Helleringer et al., 2018): (0) fell off; (1) clung to the bar with two forepaws; (2) attempted to climb on to the bar besides clinging to it with two forepaws; (3) hung on to the bar with two forepaws and one or both hind paws; (4) hung on to the bar with all four paws with the tail additionally wrapped around the bar; (5) escaped to one of the supports.

\section{Rotarod}

Motor coordination and learning were evaluated by using a mouse rotarod with adjustable speed and accelerating mode (Ugo Basile, Italy). Mice were habituated to the rod for 2 days prior to the test, by placing them on to non-rotating rod on the first day to test equilibrium (speed: 0 rotation per minute, $0 \mathrm{rmp}$ ) and then the second day on the rod rotating at a constant speed of rpm to evaluate basal motor coordination. The fall latency was recorded with a $180 \mathrm{~s}$ cut-off duration. Ina second study phase, motor synchronization learning was tested for three consecutive days by placing the mice on the rotating rod with an acceleration protocol (4 to $40 \mathrm{rpm}$ in $5 \mathrm{~min}$ ). Mice were submitted to five training sessions, one session on the first training day and then two daily sessions during day 2 and day 3. Each session was composed of five successive trials. Between each trial the mouse was placed back in its cage for a minimum of $5 \mathrm{~min}$ to recover from physical fatigue. The fall latency recorded during the five trials of a session was averaged for each mouse. Motor learning performance was assessed by comparing the changes in mean fall latency across the five successive sessions in the two genotypes.

\section{Statistical Analysis}

All data are presented as mean \pm standard error. Behavioral differences between groups were verified using two-way ANOVAs with repeated measures (training days, trials). Patch-clamp recordings, immunohistochemistry and electron microscopy quantifications were compared using unpaired $t$-test. $p<0.05$ was used to define statistical significance. Statistics were performed using the Statview 5.0 (SPSS, United States) or GraphPad version 5.0 (Prism) softwares.

\section{RESULTS}

\section{Dystroglycan Is Essential for Assembly of the Dystrophin-Glycoprotein Complex in Purkinje Cells}

To start addressing the role of two major constituents of the DGC, dystrophin and DG, we analyzed specific mouse models in which one of these proteins was missing. We first analyzed $m d x$ mice, a murine model of Duchenne muscular dystrophy (DMD) lacking full length $(427 \mathrm{kDa})$ dystrophin. As previously reported (Knuesel et al., 1999; Brunig et al., 2002; Patrizi et al., 2008), labeling of dystrophin, $\alpha$-DG and $\beta$-DG can be detected in large perisomatic and dendritic clusters along PCs (Figure 1A), where these molecules co-localize precisely with $\mathrm{GABA}_{\mathrm{A}}$ Rs and NL2 (Patrizi et al., 2008). Surprisingly, the lack of dystrophin in $m d x$ mice affected the synaptic localization of $\beta$-DG without altering the localization of $\alpha$-DG (Figures 1A,B). Thus, $\alpha-D G$ and $\beta$-DG have different dependencies on dystrophin in GABAergic synapses.

We then evaluated the role of DG at the GABAergic postsynaptic compartment. First, we analyzed the distribution of DG using immunogold labeling and electron microscopy with an antibody against $\alpha$-DG. Ultrastructural analyses confirmed that in $c-W T$ cerebella labeling for $\alpha$-DG was present in symmetric synaptic specializations of PCs (Figure 1C, left). Gold particles were mainly localized in the synaptic cleft, consistent with an extracellular localization of $\alpha$-DG (Figure 1C, right). Moreover, labeling for $\alpha$-DG was observed in the basal lamina surrounding brain capillaries (Figure 1D) (Nickolls and Bonnemann, 2018). Then, we generated conditional DG KO mice by crossing mice harboring loxP sites in Dagl gene $(\operatorname{Dag} 1 \operatorname{loxP} / \operatorname{lox} P)($ Cohn et al., 2002) with the L7Cre transgenic line (L7Cre ${ }^{\mathrm{Tg} / \mathrm{Tg}}$ ), which exhibits a selective Cre recombinase expression in PCs (PC- $\Delta \mathrm{DG}$; L7Cre $\mathrm{Tg} /+$, Dag1 loxP/loxP $)$. PC$\triangle \mathrm{DG}$ mice appeared healthy and showed no obvious neurological abnormalities (not shown). Interestingly, we found that $\alpha$-DG immunoreactivity was gradually lost starting in the second and third postnatal weeks. Thus, in P16 mice labeling of PCs had a mosaic-like pattern, characterized by immunopositive ( $\alpha$-DGpos) and immunonegative ( $\alpha$-DG-neg) cells, which in several cases were adjacent (Figure 1E). At these early stages, only a small percentage of PCs had lost DG immunoreactivity, whereas at P45 more than 50\% of PCs were $\alpha$-DG-neg (Figure 1F). By the age of P90, the large majority of PCs were DG-neg (Figure 1F). This mosaic-like pattern is consistent with the asynchronous expression of L7 in different PCs (Barski et al., 2000; Briatore et al., 2010). Immunogold labeling in P90 PC$\Delta \mathrm{DG}$ mice showed an almost complete elimination of $\alpha$-DG from synaptic profiles, where gold particles were found only occasionally (Figure 1G), confirming the selective ablation of DG from PCs. Notably, ablation of DG was enough for the complete disappearing of dystrophin from post-synaptic compartments (Figure 1H), demonstrating that the synaptic localization of dystrophin depends on DG in vivo, as previously reported in forebrain neurons (Levi et al., 2002; Früh et al., 2016).

We then evaluated the functional consequences of DG loss from PCs in P90 mice, when the majority of PCs were $\alpha$-DG-neg. 
A

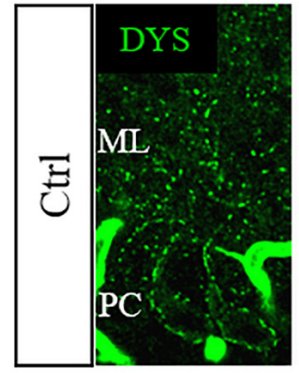

C

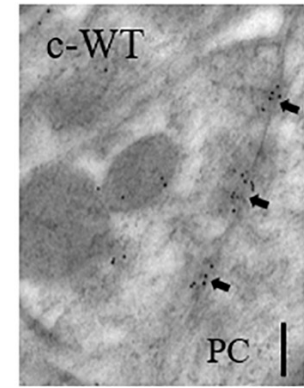

F

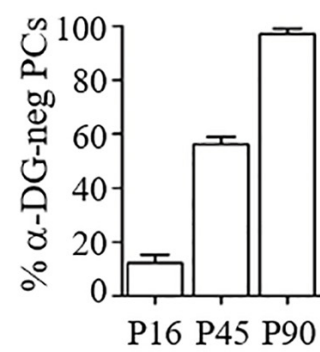

B
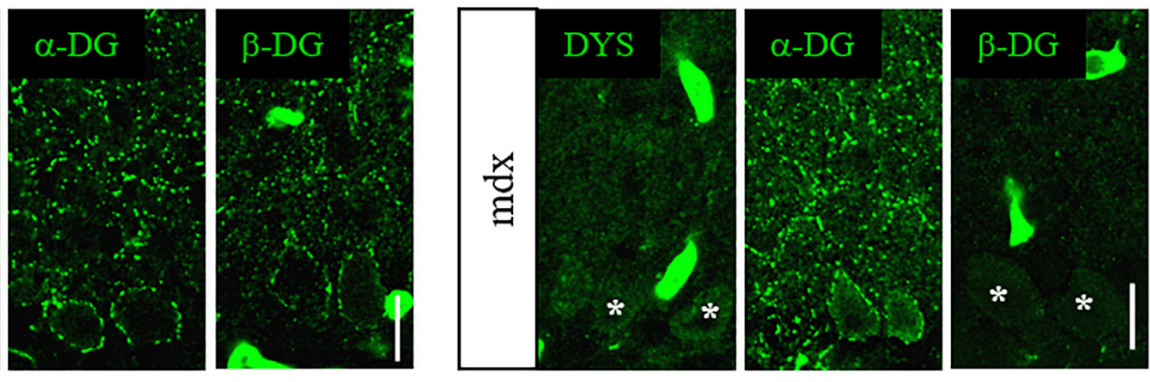

D

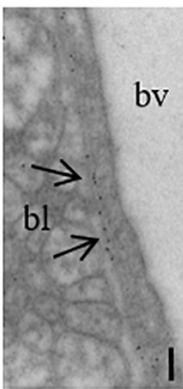

E
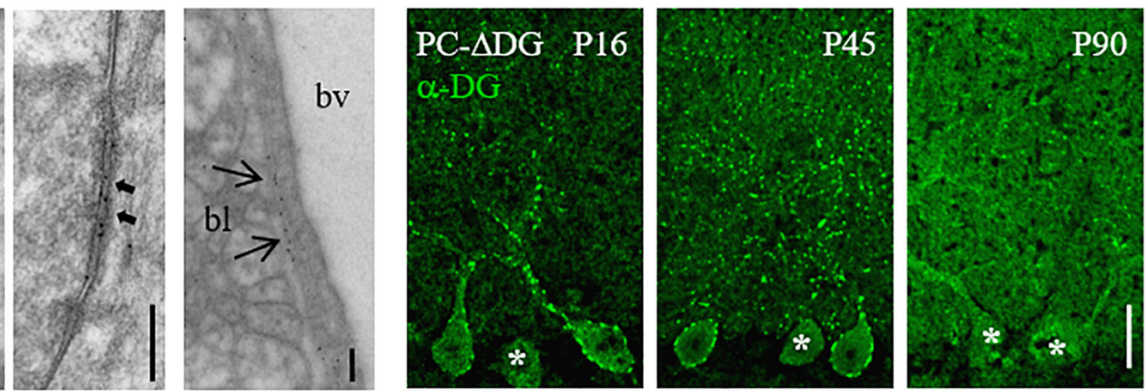

G

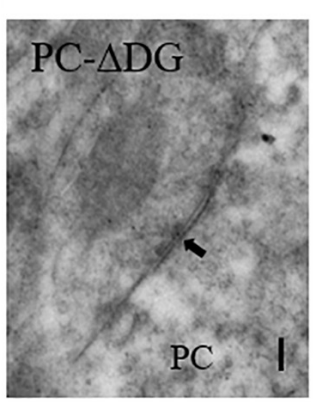

H
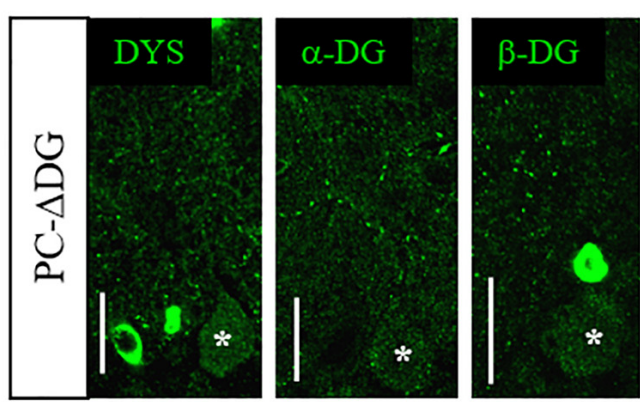

I

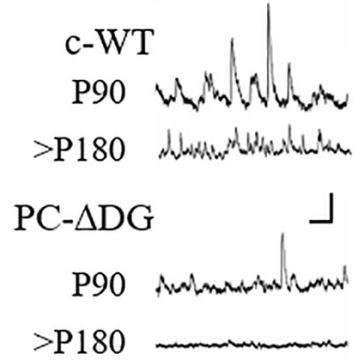

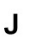

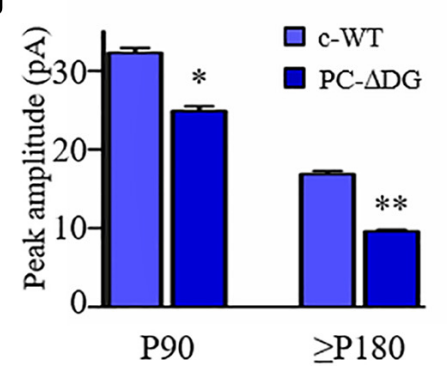

K

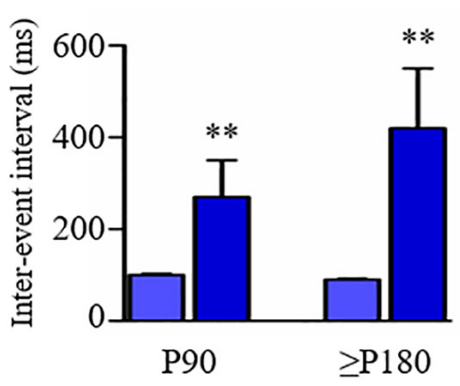

FIGURE 1 | Organization and function of the DGC at GABA synapses. (A) Representative confocal images showing immunofluorescence labeling for dystrophin (DYS), $\alpha$-dystroglycan (DG) and $\beta$-DG in adult control (Ctrl) cerebellum. Note punctate staining outlining the cell body of Purkinje cells (PCs) and their dendrites in the molecular layer (ML). (B) Immunofluorescence labeling for DYS, $\alpha$-DG and $\beta$-DG in adult $m d x$ cerebellum. PCs show labeling for $\alpha$-DG but are immunonegative for DYS and $\beta$-DG. (C) Immunogold labeling of a control (C-WT) mouse reveals the presence of $\alpha$-DG at symmetric synaptic specializations on PCs. The left panel shows an axon terminal contacting the cell body of a PC. Labeling for $\alpha$-DG is concentrated selectively at the active zones (arrows). The right panel shows a symmetric synapse (arrows) at higher magnification. Note that gold particles mainly localize in the synaptic extracellular space. (D) Immunogold labeling for $\alpha$-DG at the basal lamina (bl) of a blood vessels (bv). (E) Immunostaining for $\alpha$-DG in PC- $\triangle \mathrm{DG}$ mice of different ages shows the progressive ablation of DG from PCs. Asterisks identify $\alpha$-DG-negative PCs. (F) Quantification of $\alpha$-DG-negative PCs cells at different ages $(n=71$ cells at P16, $n=176$ cells at P45, $n=71$ cells at P90, 2-4 mice per age). (G) Immunogold labeling for $\alpha$-DG in a PC- $\Delta$ DG cerebellum shows an unlabeled symmetric synapse (arrow). (H) Representative confocal images of DYS, $\alpha$-DG and $\beta$-DG immunofluorescence in the cerebellum of P90 PC- $\triangle \mathrm{DG}$ mice. Note the dramatic reduction of cluster density for the three constituents of the DGC. (I) Representative traces of sIPSCs recorded from c-WT and PC- $\triangle$ DG cells at P90 and P180. Vertical bar: 50 pA; horizontal bar: 250 ms. (J,K) Quantitative analysis showing reduced amplitude $\mathbf{( J )}$ and frequency $\mathbf{( K )}$ of sIPSCs recorded from PCs of PC- $\Delta$ DG mice $(n=7-8$ cells, two mice) compared to control littermates (C-WT, $n=9$ cells, two mice). Unpaired $t$-test. * $p<0.05 ;{ }^{*} p<0.01$. Data represent mean \pm SEM. Scale bar: $20 \mu m$ (A,B,E,H); 200 nm (C,D,G). 
Spontaneous inhibitory post-synaptic currents (IPSCs) measured from PCs by patch-clamp recordings in acute cerebellar slices revealed a significant reduction of both the amplitude and frequency of iPSCs in PC- $\triangle \mathrm{DG}$ mice compared to $\mathrm{c}$-WT littermate controls (Figures 1I-k). This difference became even stronger in older PC- $\triangle \mathrm{DG}$ mice (Figures 1I-k), suggesting that deletion of DG causes a progressive decrease in the number of functional synapses in the cerebellum.

These data indicate that the DGC is important for inhibitory synapse organization and function. Moreover, mutation of selective DGC components differentially affects the molecular organization of GABAergic synapses.

\section{Dystroglycan Promotes the Clustering of GABAergic Post-synaptic Components}

To understand how the DGC organizes GABAergic synapses, we used immunofluorescence with antibodies raised against post-synaptic proteins. Inhibitory synapses onto PCs express a homogenous repertoire of post-synaptic molecules, including $\mathrm{GABA}_{\mathrm{A}}$ Rs with the $\alpha 1$ and $\gamma 2$ subunits, NL2 and gephyrin, together with dystrophin and DG (Patrizi et al., 2008). We therefore analyzed the clustering organization of NL2, GABA $\mathrm{As}$ and gephyrin in $m d x$ and control mice. Surprisingly, these analyses failed to reveal any significant difference between the two genotypes (Figures 2A,B), suggesting that dystrophin is not an absolute requirement for clustering of GABAergic post-synaptic molecules in PCs.

We then analyzed the molecular organization of GABAergic synapses in PCs of PC- $\triangle \mathrm{DG}$ mice. In control condition, $\alpha$-DG precisely co-localized with $\mathrm{GABA}_{\mathrm{A}} \mathrm{R} \alpha 1$ and NL2 (Patrizi et al., 2008) (Figures $\mathbf{2 C}_{1}, \mathbf{D}_{1}$ ). In contrast, clustering of both NL2 and $\mathrm{GABA}_{\mathrm{A}} \mathrm{R} \alpha 1$ was severely altered in $\alpha$-DGneg PCs (Figures $2 \mathbf{C}_{2}, \mathbf{D}_{2}$ ). Quantitative analyses showed an extensive ablation of $\mathrm{NL} 2$ and $\mathrm{GABA}_{\mathrm{A}} \mathrm{R} \alpha 1$ in the somatic and dendritic compartments of DG-mutant PCs compared to control littermates (Figures 2E,F). The sporadic puncta that remained detectable along the $\mathrm{PC}$ profiles of $\mathrm{PC}-\triangle \mathrm{DG}$ mice (Figures $2 \mathrm{C}_{2}, \mathbf{D}_{2}$ ) generally had a small size and a weak fluorescence intensity, suggesting impaired aggregation of postsynaptic proteins. Accordingly, the density of dendritic gephyrin clusters was also significantly reduced in PC- $\triangle \mathrm{DG}$ mice (cWT: $16.1 \pm 1.6$ clusters $/ 100 \mu \mathrm{m}$; PC- $\Delta \mathrm{DG}$ : $8.6 \pm 0.8 ; n=3$ mice; $p=0.0059)$. These results indicate that selective ablation of DG from individual PCs strongly affects GABAergic postsynaptic constituents.

Similar results were obtained by comparing $\alpha$-DG-pos and $\alpha$-DG-neg PCs in younger (P45) animals (Figure 3). Interestingly, there was a gradient in the elimination of DG from the cell body and the dendrites of PCs, that was mirrored by a gradual loss of NL2 (Figure 3A). At these early stages, rare NL2 clusters lacking $\alpha-D G$ could be identified along PC dendrites (Figure 3B), likely representing a transient phase of post-synaptic rearrangement. Quantification at P45 and P90 revealed that conditional knockout of DG caused a disappearance of almost $60 \%$ of perisomatic NL2 and $\mathrm{GABA}_{\mathrm{A}} \mathrm{R} \alpha 1$ clusters at both ages (Figure $3 \mathrm{C}$ ). On the other hand, the reorganization of axodendritic synapses was slower, resulting in a 50\% cluster reduction only at P90 (Figure 3D). These results indicate that perisomatic synapses are more susceptible to ablation of DG. It is tempting to link this to the fact that mature perisomatic synapses lack gephyrin (Viltono et al., 2008).

S-SCAM is a scaffolding protein essential for the clustering of synaptic receptors and the dynamic turnover of synaptic components (Danielson et al., 2012). At GABAergic synapses, S-SCAM interacts with key post-synaptic molecules, such as $\beta$-DG and NL2 (Sumita et al., 2007). We therefore analyzed how the absence of DG affects S-SCAM localization in PCs. In control mice, we noticed that the majority of S-SCAM-positive puncta co-localized with $\alpha$-DG, suggesting a preferential association of S-SCAM with GABAergic synapses. Interestingly, in PC$\triangle \mathrm{DG}$ mice $\alpha$-DG-neg PCs showed a significant downregulation of S-SCAM clusters, whereas $\alpha$-DG-pos PCs did not differ from littermate controls (Figures 2G,H). In the molecular layer, practically all S-SCAM clusters were associated with DG clusters, suggesting that their density was strongly reduced after ablation of DG (Figure 2I). These data indicate that in PCs S-SCAM localization at GABA synapses requires DG.

All together, our findings indicate that DG is essential for organizing GABAergic post-synaptic assemblies. Deletion of DG dramatically affects all major GABAergic post-synaptic components, including $\mathrm{GABA}_{\mathrm{A}} \mathrm{Rs}$, the cell adhesion molecule NL2 and the scaffolding proteins S-SCAM and gephyrin.

\section{Dystroglycan Is Required for GABAergic Innervation}

Both DG and NL2 can bind to presynaptic NRXs (Sugita et al., 2001), suggesting that these molecules may play a role in transsynaptic adhesion. Therefore, we decided to investigate to what extent the deletion of DG, and the resulting loss of NL2, affects presynaptic GABAergic innervation. To evaluate the presynaptic compartment, we used an antibody raised against the vesicular inhibitory amino acid transporter (VGAT), which is responsible for GABA uptake and storage in synaptic vesicles. We observed a significant reduction in the density of VGAT-positive terminals contacting PCs (Figure 4A), both in the somatic and dendritic domains (Figure 4B), suggesting that the absence of DG affects GABAergic afferents. Notably, the organization of the pinceau at the axon initial segment of PCs was not overtly altered in PC$\triangle \mathrm{DG}$ mice (Figure 4A); in fact both the mean labeling intensity and the overall area of the VGAT-positive terminals at the pinceau were indistinguishable in the two genotypes (Figures 4C,D), consistent with the fact that the pinceau lacks the protein machinery typical of GABAergic synapses (Iwakura et al., 2012).

The observations reported above may reflect diminished expression of VGAT in presynaptic terminals and/or reduced GABAergic innervation of PCs. To distinguish between these possibilities, we investigated the expression of another presynaptic protein, bassoon, and we found a dramatic decrease in the density of perisomatic bassoon-positive puncta in PC$\triangle \mathrm{DG}$ PCs (Figures 4E,F). Because bassoon is also present in excitatory synapses, we did not assess its expression in the molecular layer due to the very high density of puncta. 
A

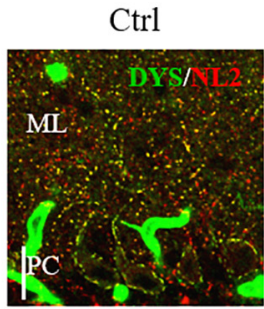

C1

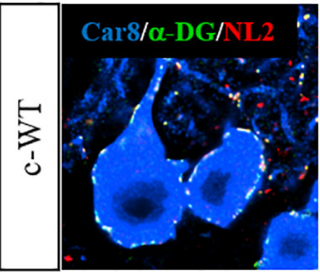

D1

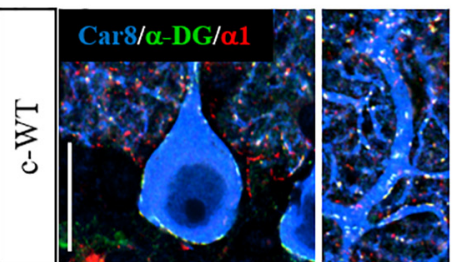

$\mathrm{mdx}$

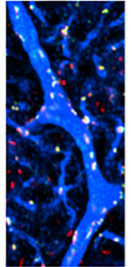

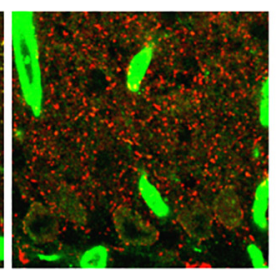

C2

D2
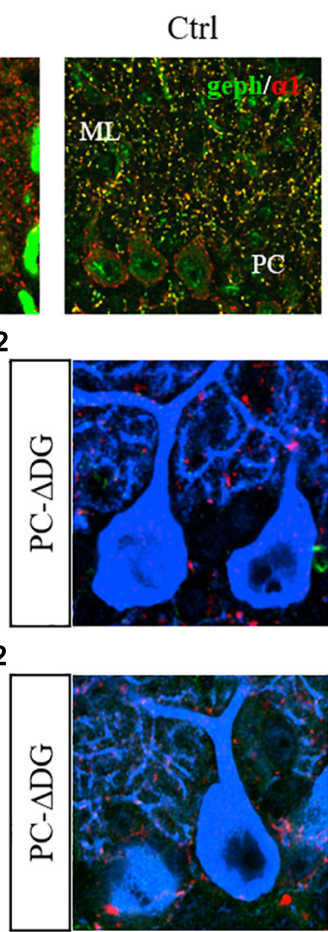

2

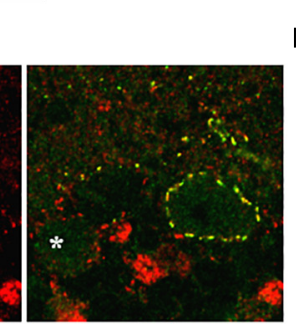

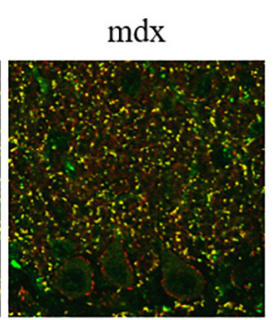

E
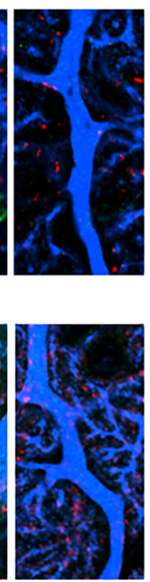

H

F

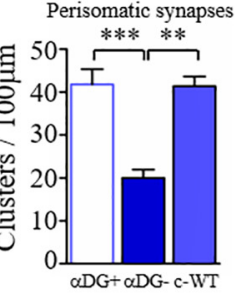

B

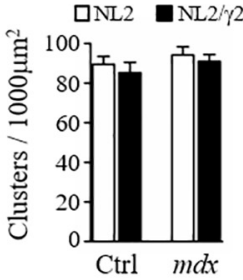

Ctrl $m d x$
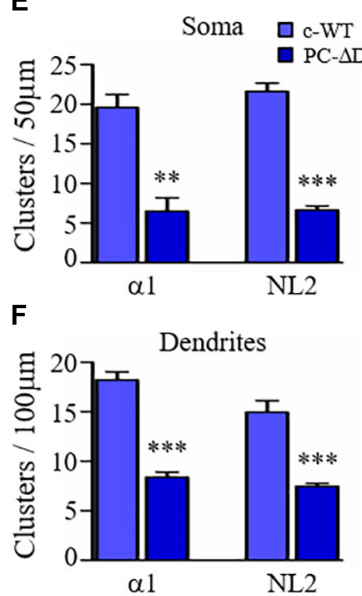

$\alpha 1$

NL2

I

Molecular layer
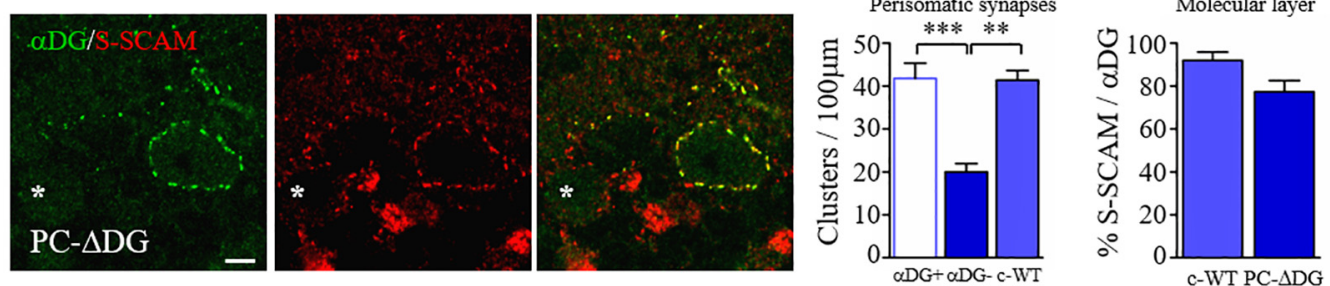

FIGURE 2 | Dystroglycan is required for clustering of post-synaptic proteins. (A) Organization of GABAergic post-synaptic molecules in $m d x$ and control (Ctrl)

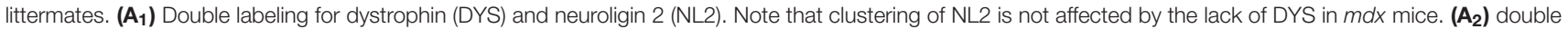
labeling for gephyrin (geph) and $\mathrm{GABA}_{A} R \alpha 1$ reveals no obvious difference between control and mutant mice. Note that gephyrin clusters are normally not present at perisomatic synapses of PCs. ML: molecular layer. (B) Quantification showing similar densities of NL2 and GABA $R \gamma 2$ clusters in the molecular layer of Ctrl and $m d x$

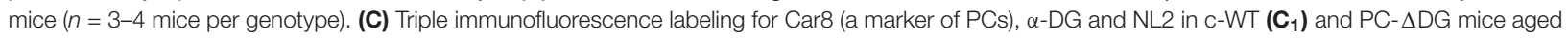
$\sim 3$ months $\left(\mathbf{C}_{\mathbf{2}}\right)$. In c-WT mice, NL2 colocalizes with $\alpha$-DG (triple labeling results in white puncta). In contrast, NL2 clusters are almost completely absent from PCs of PC- $\triangle D G$ mice. The NL2-positive clusters visible outside of PCs (red puncta) represent synapses on cerebellar interneurons, which do not normally express DG. (D) Triple labeling for Car8, $\alpha-D G$ and GABA $A_{A} \alpha 1$ in c-WT and PC- $\triangle D G$ mice. GABA $A_{A} R \alpha 1$ colocalizes with $\alpha-D G$ in c-WT PCs $\left(\mathbf{D}_{1}\right)$, whereas GABA $A_{A} R_{1}$ clusters are almost completely absent from PCs of PC- $\triangle \mathrm{DG}$ mice $\mathbf{( D}_{\mathbf{2}} \mathbf{)}$. Quantitative analysis showing the density of somatic $\mathbf{( E )}$ and axodendritic $(\mathbf{F}) \mathrm{GABA} \mathrm{A}_{\mathrm{A}} \mathrm{R} \alpha 1$ and $\mathrm{NL2}$ clusters in control and PC- $\triangle \mathrm{DG}$ mice ( $n=3$ mice per genotype). (G) Representative confocal images showing immunofluorescence labeling for $\alpha$-DG and S-SCAM in a P90 PC- $\triangle$ DG cerebellum. S-SCAM colocalizes precisely with $\alpha$-DG in a $\alpha$-DG-positive PC, whereas the density of S-SCAM clusters is reduced in $\alpha$-DG-negative PC (asterisk). (H) Quantitative analysis of the density of perisomatic S-SCAM clusters does not show any difference between c-WT and $\alpha$-DG-positive PCs ( $\alpha$ DG + ). In contrast, S-SCAM is significantly downregulated in $\alpha$-DG-negative PCs ( $\alpha$ DG-) compared to c-WT littermates $(n=8-10$ cells per genotype, four mice per genotype). (I) The percentage of S-SCAM clusters colocalized with $\alpha$-DG in the molecular layer was similar in PC- $\Delta D G$ and $c-W T$ mice. Unpaired $t$-test. ${ }^{* *} p<0.01$; ${ }^{* * *} p<0.001$. Data represent mean \pm SEM. Scale bar: $20 \mu \mathrm{m}$ (A,C,D), $5 \mu \mathrm{m}$ (G).

Finally, we used electron microscopy to analyze the density of presynaptic boutons establishing contacts with the cell body of PCs. This ultrastructural analysis revealed a remarkable (almost $50 \%)$ decrease of perisomatic contacts in PCs of PC- $\Delta \mathrm{DG}$ mice (Figures 5A-C). The axon terminals establishing these symmetric junctions were very similar to those seen in control animals, although some were characterized by a paucity of presynaptic vesicles (Figure 5B). Heterologous contacts made by climbing fibers or other glutamatergic axons were not observed. Thus, it is likely that the residual symmetric synapses on mutant PCs are made by molecular layer interneurons. Together, these data indicate that DG plays a pivotal role in trans-synaptic signaling required for the maintenance of GABAergic synapses in PCs.

Finally, we investigated whether DG mutants have impaired motor performances and motor learning. PC- $\triangle \mathrm{DG}$ mice showed no obvious signs of tremor or ataxia (not shown). In contrast, the accelerating rotarod test revealed significantly impaired motor 
A P45 PC- $\Delta \mathrm{DG}$

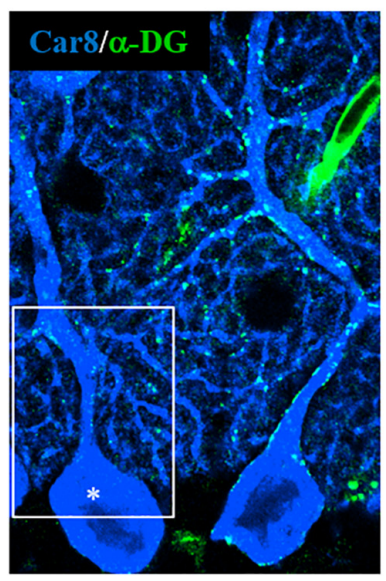

C

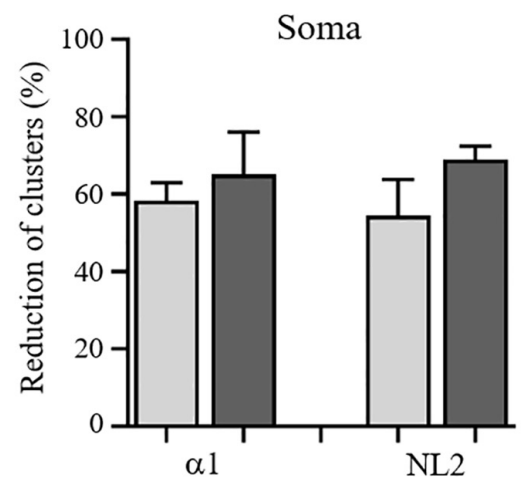

B

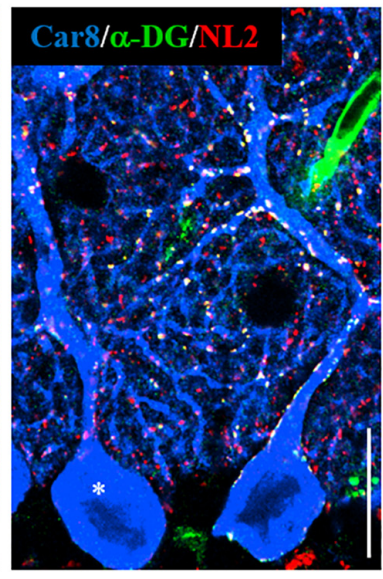

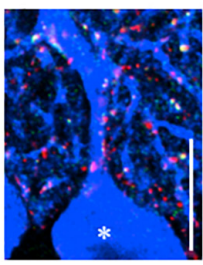

D

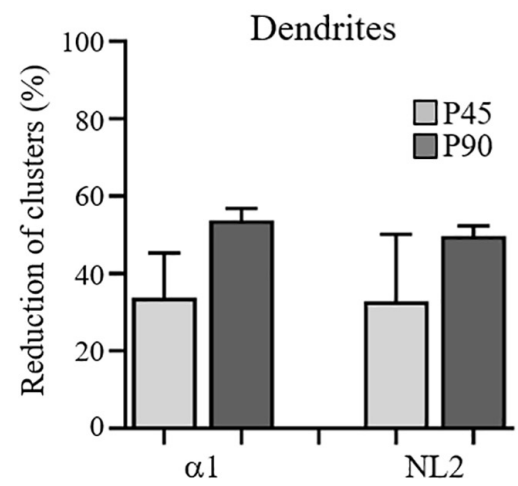

FIGURE 3 | Gradual disappearance of $\alpha$-dystroglycan from Purkinje cells. (A) Triple immunofluorescence labeling for Car8, $\alpha$-DG and NL2 in a P45 PC- $\Delta$ DG cerebellum showing adjacent $\alpha$-DG-positive and $\alpha$-DG-negative (asterisk) PCs. In the $\alpha$-DG-positive PC, $\alpha$-DG and NL2 colocalize precisely at the perisomatic and dendritic clusters, whereas in the $\alpha$-DG-negative PC there is a somatodendritic gradient in the loss of $\alpha$-DG and NL2-positive puncta. (B) White box insert shows the residual presence of $\alpha-D G$ and NL2 clusters along the dendritic domain of the $\alpha$-DG-negative PC. Quantitative analysis showing the reduction of the GABA $A_{A} 1$ and NL2 perisomatic (C) and dendritic (D) clusters at P45 and P90 ( $n=3$ mice per genotype). Data represent mean \pm SEM. Scale bar: $15 \mu \mathrm{m}$.

learning performance in the mutants (Figure 6A). Indeed, during the accommodation period (rpm 0 and rpm 4) the two groups showed a comparable fall latency, suggesting unaltered static equilibrium and basal dynamic coordination, respectively. In contrast, during the acceleration phase (day 1 to day 3 ) the motor abilities improved in control but not in mutant mice (Figure 6A). We did not find significant differences between PC$\triangle \mathrm{DG}$ and $\mathrm{c}$-WT mice in the inverted screen (not shown) and wire suspension tests (Figure 6B), thus, confirming that muscle strength and basal motor coordination were not affected in PC$\triangle \mathrm{DG}$. These data suggest that selective deletion of DG from PCs causes a severe alteration of GABAergic synaptic compartments, leading to impaired motor synchronization learning.

\section{DISCUSSION}

DG is a central component of the DGC, which links the cytoskeleton to the extracellular matrix in different cell types. Mutations affecting DGC components lead to muscular dystrophies with variable degrees of central nervous system involvement (Barresi and Campbell, 2006; Godfrey et al., 2011). Deletion of DG selectively from neurons causes subtle defects, such as altered long-term potentiation in the hippocampus (Satz et al., 2010), but the precise mechanisms by which DG regulates synaptic function and plasticity remain unknown. In this study, we dissected DG function in cerebellar PCs. The major findings are summarized in Figure 7. Briefly, we show that DG is a crucial organizer of GABA synapses, linking structural scaffolding proteins with synaptic cell-adhesion molecules. In particular, selective ablation of DG from PCs disrupts the clustering of major constituents of the GABAergic post-synaptic protein network, causing reduced GABAergic currents and delayed learning of motor synchronization. The drastic alteration of the post-synaptic compartment in DG-deprived PCs is accompanied by a severe reduction of GABAergic innervation, suggesting that DG is required for synapse maintenance. Remarkably, these synaptic alterations were not present in 
A

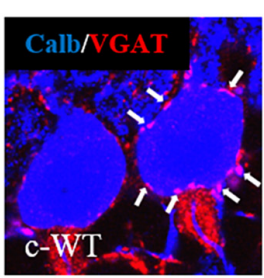

E

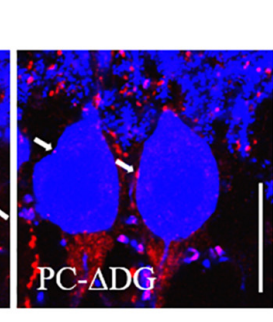

B

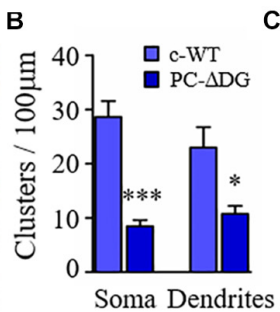

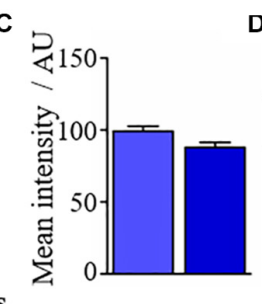

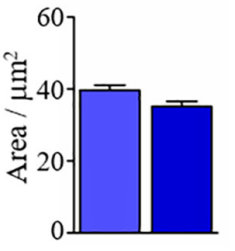

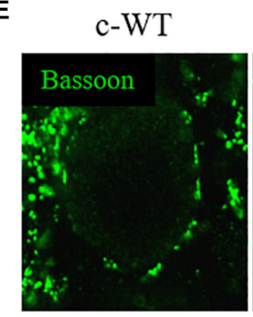

PC- $\Delta \mathrm{DG}$

F
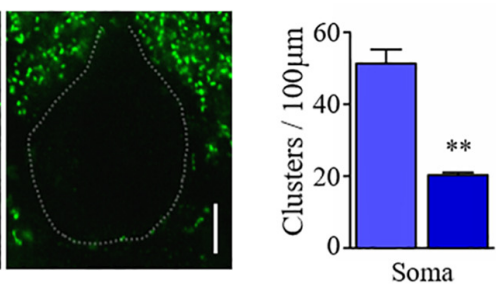

FIGURE 4 | Dystroglycan is required for GABAergic innervation. (A) Double immunofluorescence labeling for VGAT and calbindin (calb) showing the perisomatic arrangement of GABAergic presynaptic terminals (white arrows) in PCs of control (c-WT) and PC- $\triangle \mathrm{DG}$ mice aged $\sim 3$ months. (B) Quantitative analysis showing that perisomatic appositions by VGAT-positive elements are dramatically reduced in PCs of PC- $\triangle D G$ mice. (C,D) Quantitative analysis showing no differences in the pinceau mean intensity and mean area between c-WT and PC- $\Delta$ DG mice ( $n=3-5$ mice per genotype). (E) Immunofluorescence labeling showing the arrangement of bassoon-positive clusters surrounding PCs in c-WT and PC- $\triangle \mathrm{DG}$ mice aged $\sim 3$ months. (F) Quantitative analysis showing the significant reduction of bassoon-positive perisomatic clusters in PCs of PC- $\Delta$ DG mice $\left(n=3-4\right.$ mice per genotype). Unpaired $t$-test, ${ }^{\star} p<0.05 ;{ }^{* \star} p<0.01 ;{ }^{\star \star \star} p<0.001$.

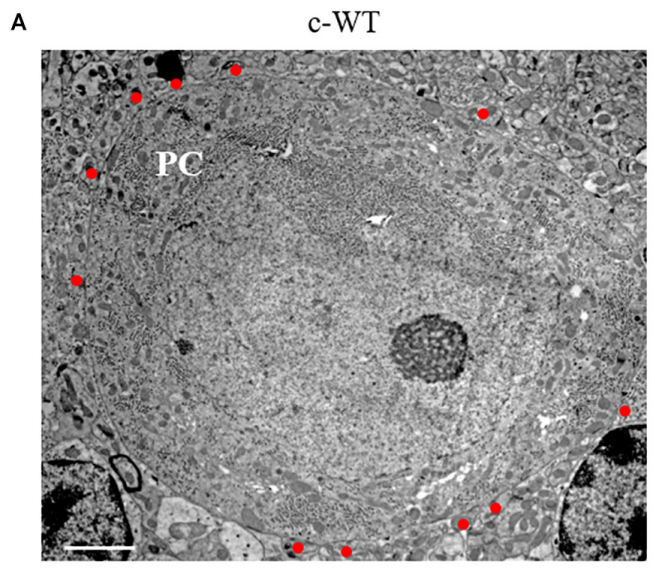

B

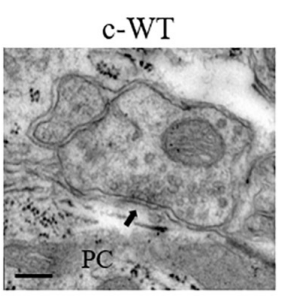

$\mathrm{PC}-\Delta \mathrm{DG}$

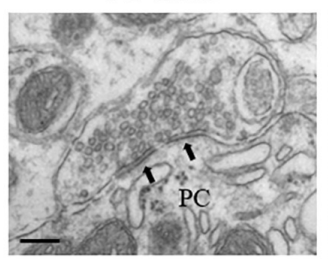

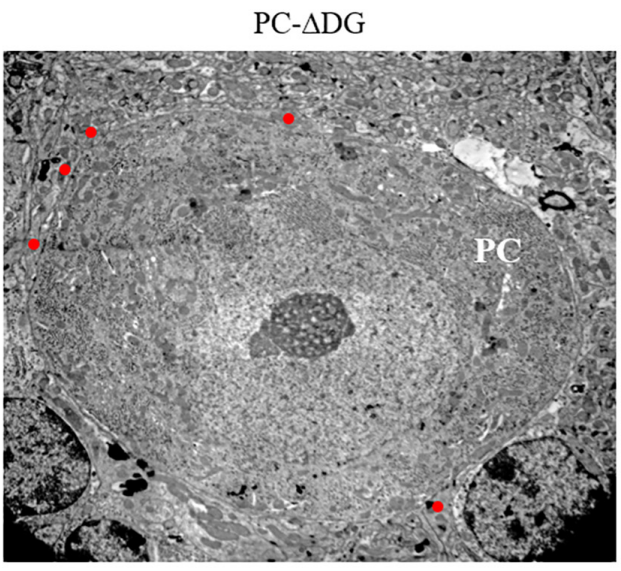

C

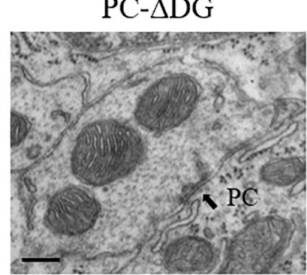

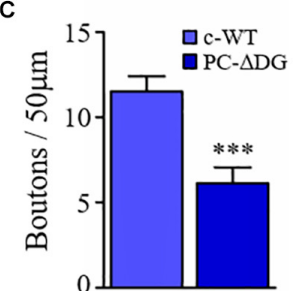

FIGURE 5 | GABAergic synapse elimination in PC- $\triangle$ DG mice. (A) Representative electron micrographs showing PCs of c-WT and PC- $\triangle D G$ mice. Red dots identify GABAergic axon terminals establishing symmetric synaptic contacts. (B) Perisomatic synapses shown at higher magnification. Arrows point to symmetric synaptic specializations. (C) Quantitative analysis showing a significant reduction of axon terminals contacting PC somas in PC- $\Delta$ DG mice compared with c-WT ( $n=8-10$ PCs per genotype). Unpaired t-test. ${ }^{*} p<0.05 ;{ }^{* *} p<0.01$; ${ }^{* * *} p<0.001$. Scale bar: $2 \mu$ PC-Dm (A), 200 nm (C).

$m d x$ mice that retain $\alpha-D G$ at synapses, supporting the idea that the stability of GABAergic synapses in PCs depends on extracellular interactions mediated by $\alpha$-DG. Thus, $\alpha$-DG is a novel secreted synaptic organizer that localizes in the synaptic cleft and mediates trans-synaptic interactions in a subset of GABAergic synapses. 

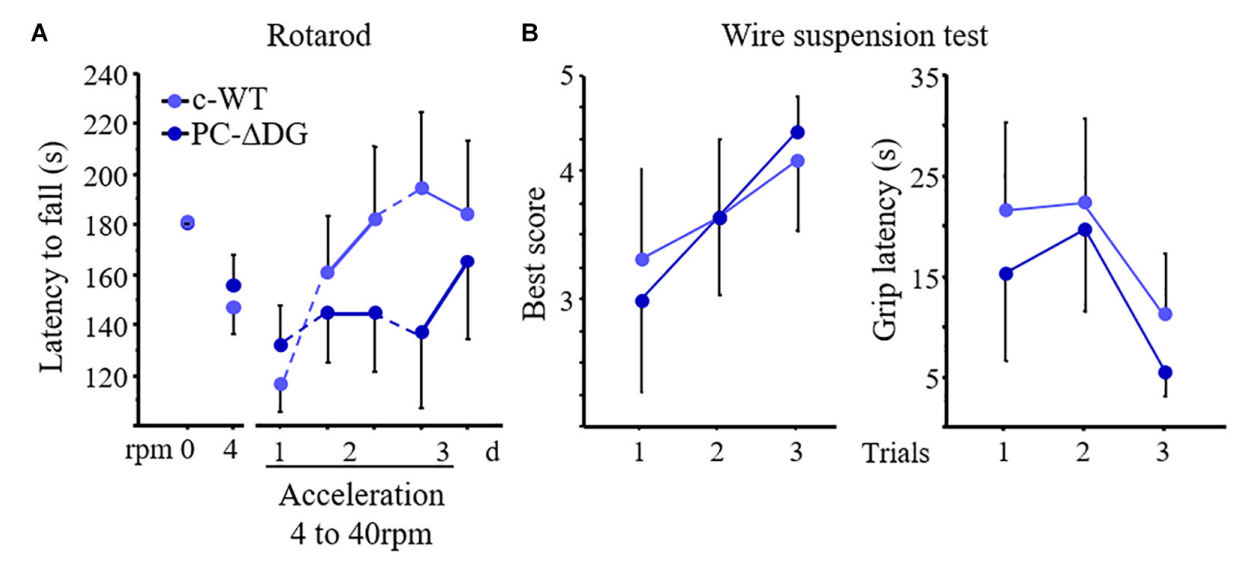

FIGURE 6 | Motor learning defects in PC- $\triangle \mathrm{DG}$ mice. (A) The latency to fall from rotarod does not differ between PC- $\triangle \mathrm{DG}$ and $\mathrm{C}-\mathrm{WT}$ littermates during the accommodation trials at 0 and 4 rotations per minute (rpm). In contrast, motor-coordination learning significantly decreases in PC- $\Delta \mathrm{DG}$ compared to $\mathrm{C}-\mathrm{WT}$ mice during the acceleration trials (4 to $40 \mathrm{rpm}$ ) developed over 3 days (d) (Two-way ANOVA, Genotype $\mathrm{x}$ session: $p<0.05, n=9$ mice per group). (B) No differences in the best score (left panel) and in the latency to grip the wire (right panel) in the wire suspension test between PC- $\Delta$ DG and c-WT controls ( $n=9$ mice per group). Data represent mean \pm SEM.

\section{Dystroglycan Is Required for Clustering of Post-synaptic Proteins}

A key finding of our study is that deletion of DG from PCs impaired the post-synaptic accumulation of major post-synaptic proteins, such as NL2, S-SCAM, gephyrin and $\mathrm{GABA}_{\mathrm{A}} \mathrm{Rs}$. Historically, it has been assumed that a subset of inhibitory synapses is dependent upon the presence of NL2 or the gephyrinand NL2-binding guanine nucleotide exchange factor (GEF) collybistin (Patrizi et al., 2008; Krueger et al., 2012). However, to our knowledge, no study has addressed the role of NL2 or other cell-adhesion molecules in the clustering of the DGC complex at central synapses. Our data suggest that in PCs DG may act upstream of NL2 as a nucleation site that governs the assembly of the GABAergic post-synaptic specialization. This is a particularly dramatic effect in light of the fact that neither synaptic $\mathrm{GABA}_{\mathrm{A}} \mathrm{Rs}$ nor collybistin are required for post-synaptic clustering of NL2 (Patrizi et al., 2008; Poulopoulos et al., 2009; Frola et al., 2013).

The clustering of NL2 by DG may appear at first surprising, because NL2 also binds presynaptically to NRX, and it is generally assumed that NRX-NL interactions represent a key step in the developmental assembly of synapses (Sudhof, 2008; Shen and Scheiffele, 2010; Siddiqui and Craig, 2011; Krueger et al., 2012). However, we have previously demonstrated that NRX expression is developmentally regulated at GABA synapses in PCs. Specifically, NRX is associated with GABAergic synapses during early postnatal development, and is downregulated in mature circuits (Pregno et al., 2013). This raises the intriguing possibility that NRX-NL2 interactions could be involved in early stages of synaptic adhesion (Craig and Kang, 2007), whereas DG stabilizes newly formed synapses. Unfortunately, this hypothesis cannot be verified in our mouse model. In fact, due to the late temporal profile of L7Cre recombinase expression in PCs (Barski et al., 2000; Briatore et al., 2010), the deletion of DG starts around the time when NRX is downregulated at GABAergic synapses (Pregno et al., 2013).
Our findings suggest that distinct components of the DGC play exquisitely specific roles in regulating the GABAergic post-synaptic protein network. In particular, the analysis of $m d x$ mice reveals that dystrophin is not essential for postsynaptic clustering of NL2, GABA ${ }_{A}$ Rs and gephyrin. Similarly, in hippocampal CA1 the absence of dystrophin did not abolish synaptic clustering of NL2 per se, although the authors reported a complex pattern of alterations in the distribution of preand post-synaptic proteins of inhibitory synapses in dystrophindeficient mice, most likely reflecting a rearrangement of the GABAergic synaptic network (Krasowska et al., 2014). Our results contrast with previous analyses revealing selective deficits in the synaptic clustering of $\mathrm{GABA}_{\mathrm{A}} \mathrm{Rs}$, but not gephyrin, in the cerebellum and amygdala of $m d x$ mice (Knuesel et al., 1999; Sekiguchi et al., 2009). However, the selective loss of $\mathrm{GABA}_{\mathrm{A}} \mathrm{R}$, but not gephyrin, clusters is surprising, also considering that deletion of $\mathrm{GABA}_{\mathrm{A}}$ Rs from PCs causes a severe defect in the clustering of gephyrin (Kralic et al., 2006; Patrizi et al., 2008), without affecting dystrophin and DG (Patrizi et al., 2008). It is important to notice that dystrophin is required for normal GABAergic function in PCs, CA1 pyramidal cells and amygdala neurons (Anderson et al., 2003; Vaillend et al., 2004; Kueh et al., 2008; Sekiguchi et al., 2009). One possible explanation, which could reconcile our data with those of Knuesel et al. (1999), is that dystrophin contributes to stabilize post-synaptic $\mathrm{GABA}_{\mathrm{A}} \mathrm{Rs}$ by regulating the trafficking of peri/extra-synaptic receptors (Vaillend and Chaussenot, 2017) and that loss of dystrophin causes subtle effects not readily detected by our sensitive immunofluorescence procedure.

While post-synaptic changes in $m d x$ mice were minor, the selective deletion of DG from PCs caused a dramatic decrease of both $\mathrm{GABA}_{\mathrm{A}}$ Rs and gephyrin clusters, accompanied by a significant downregulation of sIPSC frequency and amplitude. Our results differ from those of a recent study in which conditional deletion of DG from hippocampal 

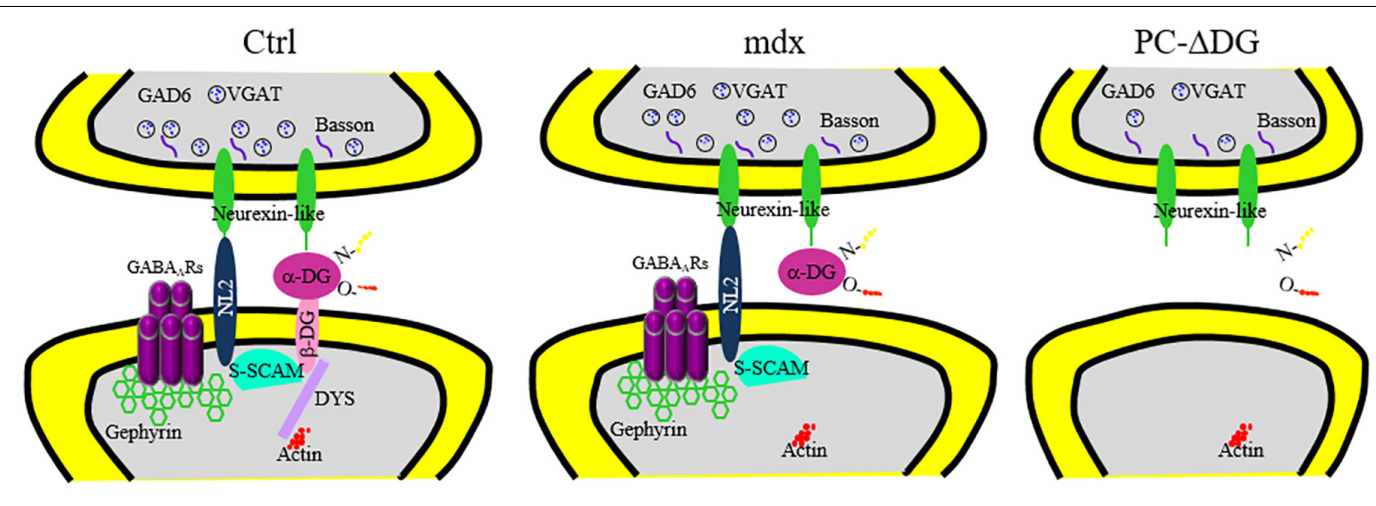

FIGURE 7 | Reorganization of major pre-and post-synaptic proteins after ablation of dystroglycan from PCs. Summary of the distribution of essential GABAergic synaptic components in PCs of control (Ctrl, left panel), $m d x$ (middle panel) and PC- $\triangle \mathrm{DG}$ mice (right panel). Briefly, $\alpha$ - and $\beta$-dystroglycan (DG) bridge presynaptic neurexin (NRX) or NRX-like proteins with post-synaptic structural proteins, such as dystrophin (DYS) and S-SCAM. In turn, S-SCAM establishes a link between neuroligin 2 (NL2) and $\beta$-DG. Note that both NL2 and $\alpha$-DG are capable of interacting with presynaptic NRX or NRX-like proteins. GABA $A_{A}$ receptors are stabilized by a submembranous lattice of gephyrin by direct interaction. In $m d x$ mice, the absence of dystrophin alters the synaptic localization of $\beta$-DG. However, $\alpha$-DG and other post-synaptic proteins are largely unaffected. Ablation of DG in PC- $\triangle$ DG mice causes impaired clustering of post-synaptic proteins and GABAergic synaptic instability.

pyramidal neurons, under the Nex promoter, only lead to minor alterations in GABAergic protein clustering (Früh et al., 2016). One possible explanation for this discrepancy is that the arrangement of the DGC may differ in PCs and telencephalic pyramidal neurons. For example, the DGC mainly localizes in perisomatic synapses of pyramidal neurons (Knuesel et al., 1999), whereas in PCs all perisomatic and axo-dendritic GABAergic synapses contain dystrophin and DG (Patrizi et al., 2008; Briatore et al., 2010). Früh et al. (2016) also reported a selective loss of GABAergic synapses established by cholecystokinin (CCK)-positive basket cells after deletion of DG, but failed to detect differences in the density of VGATpositive boutons, suggesting that overall GABAergic innervation was normal in their mutant. This raises the possibility that compensation by other basket cell terminals may have masked post-synaptic effects caused by DG deletion. However, it remains possible that DG plays a somewhat different role in different types of GABAergic synapses, requiring a better understanding of the neuron type-specific function of DG in trans-synaptic signaling.

\section{Dystroglycan Is Required for GABAergic Synapse Maintenance}

In addition to the disruption of the post-synaptic compartment, ablation of DG from PCs leads to a bona fide elimination of synapses. In particular, deletion of DG resulted in reduced GABAergic innervation of PCs, as evidenced by both immunofluorescence and electron microscopy, accompanied by a prominent downregulation of sIPSC frequencies. This is a particularly dramatic effect, considering that genetic ablation of synaptic adhesion proteins frequently does not result in synapse loss (Piechotta et al., 2006). For example, single, double or triple conditional knockout of NL1, NL2, and NL3 from PCs selectively decreases the amplitude of IPSCs in PCs but does not affect inhibitory synapse density (Zhang et al., 2015).
Our findings are reminiscent of the situation described for cerebellin 1 precursor protein (Cbln1), a glycoprotein of the complement C1q-related family secreted from granule cells axons. Cbln 1 mediates the formation and maintenance of glutamatergic synapses between parallel fibers and PC spines by binding to presynaptic NRX and to post-synaptic GluD2 (Uemura et al., 2010; Joo et al., 2011). Although the presynaptic binding partner of DG remains to be identified, our findings suggest that DG, similar to Cbln1, mediates trans-synaptic interactions that are essential for synapse maintenance. In particular, the extracellularly located $\alpha$-DG could establish a link between the post-synaptic site, through its binding to transmembrane $\beta$-DG, and the presynaptic compartment, most likely through a NRX-like molecule that remains to be identified (Figure 7). Thus, $\alpha$-DG joins the list of secreted synaptic organizers that reside in the extracellular matrix and act bidirectionally to coordinate selective interactions between the pre- and post-synaptic compartments (JohnsonVenkatesh and Umemori, 2010; Sassoe-Pognetto and Patrizi, 2017; Yuzaki, 2018). In the future, it will be important to implement transcriptional and proteomic analyses, such as single-cell RNA sequencing (Carter et al., 2018; Peng et al., 2019) and immunoprecipitation of $\alpha$-DG from murine cerebellum in combination with mass spectrometry to identify new bridge molecules.

\section{How Does the DGC Organize GABAergic Synapses?}

Comparison of the synaptic phenotype of and $m d x$ mice (Figure 7) offers the opportunity for a molecular dissection of the role of individual DGC constituents. One possible mechanism by which the DGC may contribute to stabilize GABAergic post-synaptic proteins and maintain GABA synapses involves intracellular interactions mediated by the multi-PDZ scaffold S-SCAM, which links $\beta$-DG to the NL2 cytoplasmic 
tail (Sumita et al., 2007) (Figure 7). S-SCAM, which has been implicated in the assembly of GABAergic synapses (Woo et al., 2013), also appears to form bridges between dystrophin and SynArfGEF, a guanine exchange factor for the Arf6 small GTPases, thereby establishing potential links between distinct subdomains of the inhibitory post-synaptic specialization (Fukaya et al., 2011). However, synaptic clustering of NL2, gephyrin and $\mathrm{GABA}_{\mathrm{A}}$ Rs was not overtly modified in $m d x$ mice, which lack dystrophin and $\beta$-DG (Figure 7), suggesting that intracellular interactions mediated by $\beta$-DG are not required for assembly of the GABAergic post-synaptic protein network and for synapse maintenance. Rather, our results indicate that persistence of $\alpha$-DG in $m d x$ mice is sufficient for preserving a largely intact post-synaptic specialization. We propose that the heavily glycosylated $\alpha$-DG subunit may stabilize GABAergic synapses via extracellular interactions with cell-surface proteins containing laminin G-like domains (Barresi and Campbell, 2006). The extensive glycosylation of $\alpha$-DG and the broad range of extracellular ligands suggest that this protein has the potential to act as a multidomain connector that brings together distinct complexes of proteins that act synergistically within the synaptic specialization.

NRX is a likely synaptic $\alpha-D G$ binding partner, as this protein can establish interactions with both $\alpha$-DG and NL2 (Sugita et al., 2001). However, NRX is downregulated in mature cerebellar GABAergic synapses (Pregno et al., 2013), suggesting that $\alpha$-DG could interact with other presynaptic molecules, potentially including NRX-like cell-surface proteins (Missler and Sudhof, 1998). One example is contactin associated protein-like 4 (CNTNAP4), also known as CASPR4, that has been localized presynaptically in developing murine cortical interneurons (Karayannis et al., 2014). Future studies will be needed to confirm the absence of NRX in mature GABAergic synapses onto PCs as well as to identify novel DG presynaptic binding partners.

\section{Dystroglycan Is a New Organizer of Inhibitory Synapses}

The present findings reveal that DG is a new organizer of a subset of GABAergic synapses, and support the idea that secreted proteins can act bidirectionally to coordinate interactions between the pre- and post-synaptic compartments (Yuzaki, 2018). The selective localization of DG and other DGC constituents in selected types of GABAergic synapses also suggests that these molecules are part of a molecular signature that contributes to generate synapse specificity (Sassoe-Pognetto and Patrizi, 2017). Indeed, GABAergic synaptic specializations differ molecularly and functionally in different interneuron subtypes throughout the brain (Contreras et al., 2019), but our understanding of the distribution and function of selective trans-synaptic adhesion systems at inhibitory synapses is still incomplete. A recent study demonstrated that distinct secreted synaptic organizers selectively drive cortical GABAergic synapse formation in distinct compartments of their post-synaptic cells. For example, Cbln4 was shown to be essential for dendritic targeting of GABAergic axons, whereas leucine-rich repeat LGI family member 2 (LGI2) emerged as a promising candidate to regulate the development of perisomatic inhibitory synapses (Favuzzi et al., 2019). Together, these data support the emerging notion of a cell type-specific molecular code of GABAergic synapses, which results from the presence of multiple transsynaptic adhesion systems characterized by partially overlapping distributions and variable degrees of redundancy.

\section{DATA AVAILABILITY STATEMENT}

All datasets generated for this study are included in the article/supplementary material.

\section{ETHICS STATEMENT}

The animal study was reviewed and approved by Italian Ministry of Health (Department of Public Veterinary Health) and the ethical committee of Turin University.

\section{AUTHOR CONTRIBUTIONS}

FB, GP, AP, CV, and MS-P conceived and designed the project. FB, GP, and EF performed morphological analyses. FB, GP, EF, and AP analyzed morphological data. SD and MD performed and analyzed electrophysiology analysis. CV performed and analyzed behavioral data. AP and MS-P wrote the manuscript. All authors edited the manuscript.

\section{FUNDING}

MS-P was supported by Ministero dell'Istruzione, dell'Università e della Ricerca - MIUR project "Dipartimenti di Eccellenza 20182022" to Department of Neuroscience "Rita Levi Montalcini," Compagnia di San Paolo (grant number 2007 and progetti di Ricerca di Ateneo 2011), the Italian MIUR (Prin 2008KN7J7J); $\mathrm{CV}$ and MS-P were supported by Association Française contre les Myopathies (AFM reference no. 15299); SD was supported by CrestOptics-IIT jointLab for advanced Microscopy, the MARBEL Life2020 grant, the SynaNet H2020 program and, Sapienza intramural grant; MD was supported by Ricerche Universitarie (Sapienza Università di Roma, grant number RM116154c9E68DE1) and Istituto Pasteur Italia-Fondazione cenci Bolognetti; GP was supported by Fondazione CRT (Progetto Lagrange); AP was supported by Chica and Heinz Schaller Foundation.

\section{ACKNOWLEDGMENTS}

We thank Dr. Michael Meyer (Max Planck Institute of Neurobiology, Martinsried, Germany) and Dr. Peer Wulff (Kiel University) for the L7Cre line, Prof. Andrea Brancaccio (Università Cattolica, Rome) for useful discussions. 


\section{REFERENCES}

Anderson, J. L., Head, S. I., and Morley, J. W. (2003). Altered inhibitory input to Purkinje cells of dystrophin-deficient mice. Brain Res. 982, 280-283. doi: 10.1016/s0006-8993(03)03018-x

Barresi, R., and Campbell, K. P. (2006). Dystroglycan: from biosynthesis to pathogenesis of human disease. J. Cell. Sci. 119(Pt 2), 199-207. doi: 10.1242/ jcs.02814

Barski, J. J., Dethleffsen, K., and Meyer, M. (2000). Cre recombinase expression in cerebellar Purkinje cells. Genesis 28, 93-98. doi: 10.1002/1526-968x(200011/ 12)28:3/4<93::aid-gene10>3.0.co; $2-\mathrm{w}$

Blake, D. J., Hawkes, R., Benson, M. A., and Beesley, P. W. (1999). Different dystrophin-like complexes are expressed in neurons and glia. J. Cell. Biol. 147, 645-658. doi: 10.1083/jcb.147.3.645

Blake, D. J., Weir, A., Newey, S. E., and Davies, K. E. (2002). Function and genetics of dystrophin and dystrophin-related proteins in muscle. Physiol. Rev. 82, 291-329. doi: 10.1152/physrev.00028.2001

Briatore, F., Patrizi, A., Viltono, L., Sassoe-Pognetto, M., and Wulff, P. (2010). Quantitative organization of GABAergic synapses in the molecular layer of the mouse cerebellar cortex. PLoS One 5:e12119. doi: 10.1371/journal.pone. 0012119

Brunig, I., Suter, A., Knuesel, I., Luscher, B., and Fritschy, J. M. (2002). GABAergic terminals are required for postsynaptic clustering of dystrophin but not of GABA(A) receptors and gephyrin. J. Neurosci. 22, 4805-4813. doi: 10.1523/ jneurosci.22-12-04805.2002

Carter, R. A., Bihannic, L., Rosencrance, C., Hadley, J. L., Tong, Y., Phoenix, T. N., et al. (2018). A single-cell transcriptional atlas of the developing murine cerebellum. Curr. Biol. 28, 2910.e2-2920.e2. doi: 10.1016/j.cub.2018.07.062

Cohn, R. D., Henry, M. D., Michele, D. E., Barresi, R., Saito, F., Moore, S. A., et al. (2002). Disruption of DAG1 in differentiated skeletal muscle reveals a role for dystroglycan in muscle regeneration. Cell 110, 639-648. doi: 10.1016/s00928674(02)00907-8

Contreras, A., Hines, D. J., and Hines, R. M. (2019). Molecular specialization of GABAergic synapses on the soma and axon in cortical and hippocampal circuit function and dysfunction. Front. Mol. Neurosci. 12:154. doi: 10.3389/fnmol. 2019.00154

Craig, A. M., and Kang, Y. (2007). Neurexin-neuroligin signaling in synapse development. Curr. Opin. Neurobiol. 17, 43-52. doi: 10.1016/j.conb.2007. 01.011

Danielson, E., Zhang, N., Metallo, J., Kaleka, K., Shin, S. M., Gerges, N., et al. (2012). S-SCAM/MAGI-2 is an essential synaptic scaffolding molecule for the GluA2containing maintenance pool of AMPA receptors. J. Neurosci. 32, 6967-6980. doi: 10.1523/JNEUROSCI.0025-12.2012

Devisme, L., Bouchet, C., Gonzales, M., Alanio, E., Bazin, A., Bessieres, B., et al. (2012). Cobblestone lissencephaly: neuropathological subtypes and correlations with genes of dystroglycanopathies. Brain 135(Pt 2), 469-482. doi: 10.1093/ brain/awr357

Ervasti, J. M., and Campbell, K. P. (1993). A role for the dystrophin-glycoprotein complex as a transmembrane linker between laminin and actin. J. Cell. Biol. 122, 809-823. doi: $10.1083 /$ jcb.122.4.809

Favuzzi, E., Deogracias, R., Marques-Smith, A., Maeso, P., Jezequel, J., ExpositoAlonso, D., et al. (2019). Distinct molecular programs regulate synapse specificity in cortical inhibitory circuits. Science 363, 413-417. doi: 10.1126/ science.aau 8977

Frola, E., Patrizi, A., Goetz, T., Medrihan, L., Petrini, E. M., Barberis, A., et al. (2013). Synaptic competition sculpts the development of GABAergic axodendritic but not perisomatic synapses. PLoS One 8:e56311. doi: 10.1371/ journal.pone.0056311

Früh, S., Romanos, J., Panzanelli, P., Burgisser, D., Tyagarajan, S. K., Campbell, K. P., et al. (2016). Neuronal dystroglycan is necessary for formation and maintenance of functional CCK-positive basket cell terminals on pyramidal cells. J. Neurosci. 36, 10296-10313. doi: 10.1523/JNEUROSCI.1823-16. 2016

Fukaya, M., Kamata, A., Hara, Y., Tamaki, H., Katsumata, O., Ito, N., et al. (2011). SynArfGEF is a guanine nucleotide exchange factor for Arf6 and localizes preferentially at post-synaptic specializations of inhibitory synapses. J. Neurochem. 116, 1122-1137. doi: 10.1111/j.1471-4159.2010.07 167.x
Goddeeris, M. M., Wu, B., Venzke, D., Yoshida-Moriguchi, T., Saito, F., Matsumura, K., et al. (2013). LARGE glycans on dystroglycan function as a tunable matrix scaffold to prevent dystrophy. Nature 503, 136-140. doi: 10 . 1038/nature12605

Godfrey, C., Foley, A. R., Clement, E., and Muntoni, F. (2011). Dystroglycanopathies: coming into focus. Curr. Opin. Genet. Dev. 21, 278-285. doi: 10.1016/j.gde.2011.02.001

Grady, R. M., Wozniak, D. F., Ohlemiller, K. K., and Sanes, J. R. (2006). Cerebellar synaptic defects and abnormal motor behavior in mice lacking alpha- and betadystrobrevin. J. Neurosci. 26, 2841-2851. doi: 10.1523/JNEUROSCI.4823-05. 2006

Helleringer, R., Le Verger, D., Li, X., Izabelle, C., Chaussenot, R., BelmaatiCherkaoui, M., et al. (2018). Cerebellar synapse properties and cerebellumdependent motor and non-motor performance in Dp71-null mice. Dis. Model. Mech. 11:dmm033258. doi: 10.1242/dmm.033258

Ibraghimov-Beskrovnaya, O., Ervasti, J. M., Leveille, C. J., Slaughter, C. A., Sernett, S. W., and Campbell, K. P. (1992). Primary structure of dystrophin-associated glycoproteins linking dystrophin to the extracellular matrix. Nature 355, 696702. doi: 10.1038/355696a0

Iwakura, A., Uchigashima, M., Miyazaki, T., Yamasaki, M., and Watanabe, M. (2012). Lack of molecular-anatomical evidence for GABAergic influence on axon initial segment of cerebellar Purkinje cells by the pinceau formation. J. Neurosci. 32, 9438-9448. doi: 10.1523/JNEUROSCI.1651-12.2012

Johnson-Venkatesh, E. M., and Umemori, H. (2010). Secreted factors as synaptic organizers. Eur. J. Neurosci. 32, 181-190. doi: 10.1111/j.1460-9568.2010.07338. $\mathrm{x}$

Joo, J. Y., Lee, S. J., Uemura, T., Yoshida, T., Yasumura, M., Watanabe, M., et al. (2011). Differential interactions of cerebellin precursor protein (Cbln) subtypes and neurexin variants for synapse formation of cortical neurons. Biochem. Biophys. Res. Commun. 406, 627-632. doi: 10.1016/j.bbrc.2011.02.108

Karayannis, T., Au, E., Patel, J. C., Kruglikov, I., Markx, S., Delorme, R., et al. (2014). Cntnap4 differentially contributes to GABAergic and dopaminergic synaptic transmission. Nature 511, 236-240. doi: 10.1038/nature13248

Knuesel, I., Mastrocola, M., Zuellig, R. A., Bornhauser, B., Schaub, M. C., and Fritschy, J. M. (1999). Short communication: altered synaptic clustering of GABAA receptors in mice lacking dystrophin (mdx mice). Eur. J. Neurosci. 11, 4457-4462. doi: 10.1046/j.1460-9568.1999.00887.x

Kralic, J. E., Sidler, C., Parpan, F., Homanics, G. E., Morrow, A. L., and Fritschy, J. M. (2006). Compensatory alteration of inhibitory synaptic circuits in cerebellum and thalamus of gamma-aminobutyric acid type A receptor alpha1 subunit knockout mice. J. Comp. Neurol. 495, 408-421. doi: 10.1002/cne.20866

Krasowska, E., Zablocki, K., Gorecki, D. C., and Swinny, J. D. (2014). Aberrant location of inhibitory synaptic marker proteins in the hippocampus of dystrophin-deficient mice: implications for cognitive impairment in duchenne muscular dystrophy. PLoS One 9:e108364. doi: 10.1371/journal.pone.0108364

Krueger, D. D., Tuffy, L. P., Papadopoulos, T., and Brose, N. (2012). The role of neurexins and neuroligins in the formation, maturation, and function of vertebrate synapses. Curr. Opin. Neurobiol. 22, 412-422. doi: 10.1016/j.conb. 2012.02.012

Kueh, S. L., Head, S. I., and Morley, J. W. (2008). GABA(A) receptor expression and inhibitory post-synaptic currents in cerebellar Purkinje cells in dystrophindeficient mdx mice. Clin. Exp. Pharmacol. Physiol. 35, 207-210. doi: 10.1111/j. 1440-1681.2007.04816.x

Levi, S., Grady, R. M., Henry, M. D., Campbell, K. P., Sanes, J. R., and Craig, A. M. (2002). Dystroglycan is selectively associated with inhibitory GABAergic synapses but is dispensable for their differentiation. J. Neurosci. 22, 4274-4285. doi: 10.1523/jneurosci.22-11-04274.2002

Martin, P. T. (2005). The dystroglycanopathies: the new disorders of O-linked glycosylation. Semin. Pediatr. Neurol. 12, 152-158. doi: 10.1016/j.spen.2005.10. 003

Missler, M., and Sudhof, T. C. (1998). Neurexins: three genes and 1001 products. Trends Genet. 14, 20-26. doi: 10.1016/S0168-9525(97)01324-3

Moukhles, H., and Carbonetto, S. (2001). Dystroglycan contributes to the formation of multiple dystrophin-like complexes in brain. J. Neurochem. 78, 824-834. doi: 10.1046/j.1471-4159.2001.00466.x

Muntoni, F., Brockington, M., Godfrey, C., Ackroyd, M., Robb, S., Manzur, A., et al. (2007). Muscular dystrophies due to defective glycosylation of dystroglycan. Acta Myol. 26, 129-135. 
Nickolls, A. R., and Bonnemann, C. G. (2018). The roles of dystroglycan in the nervous system: insights from animal models of muscular dystrophy. Dis. Model. Mech. 11:dmm035931. doi: 10.1242/dmm.035931

Patrizi, A., Scelfo, B., Viltono, L., Briatore, F., Fukaya, M., Watanabe, M., et al. (2008). Synapse formation and clustering of neuroligin-2 in the absence of GABAA receptors. Proc. Natl. Acad. Sci. U.S.A. 105, 13151-13156. doi: 10.1073/ pnas.0802390105

Peng, J., Sheng, A. L., Xiao, Q., Shen, L., Ju, X. C., Zhang, M., et al. (2019). Singlecell transcriptomes reveal molecular specializations of neuronal cell types in the developing cerebellum. J. Mol. Cell. Biol. 11, 636-648. doi: 10.1093/jmcb/ mjy089

Piechotta, K., Dudanova, I., and Missler, M. (2006). The resilient synapse: insights from genetic interference of synaptic cell adhesion molecules. Cell Tissue Res. 326, 617-642. doi: 10.1007/s00441-006-0267-4

Poulopoulos, A., Aramuni, G., Meyer, G., Soykan, T., Hoon, M., Papadopoulos, T., et al. (2009). Neuroligin 2 drives postsynaptic assembly at perisomatic inhibitory synapses through gephyrin and collybistin. Neuron 63, 628-642. doi: 10.1016/j.neuron.2009.08.023

Pregno, G., Frola, E., Graziano, S., Patrizi, A., Bussolino, F., Arese, M., et al. (2013). Differential regulation of neurexin at glutamatergic and GABAergic synapses. Front. Cell. Neurosci. 7:35. doi: 10.3389/fncel.2013.00035

Pribiag, H., Peng, H., Shah, W. A., Stellwagen, D., and Carbonetto, S. (2014). Dystroglycan mediates homeostatic synaptic plasticity at GABAergic synapses. Proc. Natl. Acad. Sci. U.S.A. 111, 6810-6815. doi: 10.1073/pnas.13217 74111

Sassoe-Pognetto, M., and Ottersen, O. P. (2000). Organization of ionotropic glutamate receptors at dendrodendritic synapses in the rat olfactory bulb. J. Neurosci. 20, 2192-2201. doi: 10.1523/jneurosci.20-06-02192.2000

Sassoe-Pognetto, M., and Patrizi, A. (2017). The Purkinje cell as a model of synaptogenesis and synaptic specificity. Brain Res. Bull. 129, 12-17. doi: 10. 1016/j.brainresbull.2016.10.004

Satz, J. S., Ostendorf, A. P., Hou, S., Turner, A., Kusano, H., Lee, J. C., et al. (2010). Distinct functions of glial and neuronal dystroglycan in the developing and adult mouse brain. J. Neurosci. 30, 14560-14572. doi: 10.1523/JNEUROSCI. 3247-10.2010

Sekiguchi, M., Zushida, K., Yoshida, M., Maekawa, M., Kamichi, S., Yoshida, M., et al. (2009). A deficit of brain dystrophin impairs specific amygdala GABAergic transmission and enhances defensive behaviour in mice. Brain 132(Pt 1), 124-135. doi: 10.1093/brain/awn253

Shen, K., and Scheiffele, P. (2010). Genetics and cell biology of building specific synaptic connectivity. Annu. Rev. Neurosci. 33, 473-507. doi: 10.1146/annurev. neuro.051508.135302

Siddiqui, T. J., and Craig, A. M. (2011). Synaptic organizing complexes. Curr. Opin. Neurobiol. 21, 132-143. doi: 10.1016/j.conb.2010.08.016

Sudhof, T. C. (2008). Neuroligins and neurexins link synaptic function to cognitive disease. Nature 455, 903-911. doi: 10.1038/nature07456

Sugita, S., Saito, F., Tang, J., Satz, J., Campbell, K., and Sudhof, T. C. (2001). A stoichiometric complex of neurexins and dystroglycan in brain. J. Cell Biol. 154, 435-445. doi: 10.1083/jcb.200105003

Sumita, K., Sato, Y., Iida, J., Kawata, A., Hamano, M., Hirabayashi, S., et al. (2007). Synaptic scaffolding molecule (S-SCAM) membrane-associated guanylate kinase with inverted organization (MAGI)-2 is associated with cell adhesion molecules at inhibitory synapses in rat hippocampal neurons. J. Neurochem. 100, 154-166. doi: 10.1111/j.1471-4159.2006.04170.x

Tyagarajan, S. K., and Fritschy, J. M. (2014). Gephyrin: a master regulator of neuronal function? Nat. Rev. Neurosci. 15, 141-156. doi: 10.1038/nrn3670

Uemura, T., Lee, S. J., Yasumura, M., Takeuchi, T., Yoshida, T., Ra, M., et al. (2010). Trans-synaptic interaction of GluRdelta2 and Neurexin through Cbln1 mediates synapse formation in the cerebellum. Cell 141, 1068-1079. doi: 10. 1016/j.cell.2010.04.035

Vaillend, C., Billard, J. M., and Laroche, S. (2004). Impaired long-term spatial and recognition memory and enhanced CA1 hippocampal LTP in the dystrophindeficient Dmd(mdx) mouse. Neurobiol. Dis. 17, 10-20. doi: 10.1016/j.nbd.2004. 05.004

Vaillend, C., and Chaussenot, R. (2017). Relationships linking emotional, motor, cognitive and GABAergic dysfunctions in dystrophin-deficient mdx mice. Hum. Mol. Genet. 26, 1041-1055. doi: 10.1093/hmg/ddx013

Varoqueaux, F., Jamain, S., and Brose, N. (2004). Neuroligin 2 is exclusively localized to inhibitory synapses. Eur. J. Cell. Biol. 83, 449-456. doi: 10.1078/ 0171-9335-00410

Viltono, L., Patrizi, A., Fritschy, J. M., and Sassoe-Pognetto, M. (2008). Synaptogenesis in the cerebellar cortex: differential regulation of gephyrin and GABAA receptors at somatic and dendritic synapses of Purkinje cells. J. Comp. Neurol. 508, 579-591. doi: 10.1002/cne.21713

Woo, J., Kwon, S. K., Nam, J., Choi, S., Takahashi, H., Krueger, D., et al. (2013). The adhesion protein IgSF9b is coupled to neuroligin 2 via S-SCAM to promote inhibitory synapse development. J. Cell. Biol. 201, 929-944. doi: 10.1083/jcb. 201209132

Yamagata, M., Sanes, J. R., and Weiner, J. A. (2003). Synaptic adhesion molecules. Curr. Opin. Cell. Biol. 15, 621-632. doi: 10.1016/s0955-0674(03)00107-8

Yogev, S., and Shen, K. (2014). Cellular and molecular mechanisms of synaptic specificity. Annu. Rev. Cell. Dev. Biol. 30, 417-437. doi: 10.1146/annurevcellbio-100913-012953

Yuzaki, M. (2018). Two classes of secreted synaptic organizers in the central nervous system. Annu. Rev. Physiol. 80, 243-262. doi: 10.1146/annurevphysiol-021317-121322

Zhang, B., Chen, L. Y., Liu, X., Maxeiner, S., Lee, S. J., Gokce, O., et al. (2015). Neuroligins sculpt cerebellar purkinje-cell circuits by differential control of distinct classes of synapses. Neuron 87, 781-796. doi: 10.1016/j.neuron.2015. 07.020

Conflict of Interest: The authors declare that the research was conducted in the absence of any commercial or financial relationships that could be construed as a potential conflict of interest.

Copyright (C) 2020 Briatore, Pregno, Di Angelantonio, Frola, De Stefano, Vaillend, Sassoe-Pognetto and Patrizi. This is an open-access article distributed under the terms of the Creative Commons Attribution License (CC BY). The use, distribution or reproduction in other forums is permitted, provided the original author(s) and the copyright owner(s) are credited and that the original publication in this journal is cited, in accordance with accepted academic practice. No use, distribution or reproduction is permitted which does not comply with these terms. 